\title{
Proteomic Approaches and Identification of Novel Therapeutic Targets for Alcoholism
}

\author{
Giorgio Gorini,1 ${ }^{*}$ R Adron Harris ${ }^{1}$ and R Dayne Mayfield ${ }^{1}$ \\ ${ }^{1}$ Waggoner Center for Alcohol and Addiction Research, The University of Texas at Austin, Austin, TX, USA
}

\begin{abstract}
Recent studies have shown that gene regulation is far more complex than previously believed and does not completely explain changes at the protein level. Therefore, the direct study of the proteome, considerably different in both complexity and dynamicity to the genome/transcriptome, has provided unique insights to an increasing number of researchers. During the past decade, extraordinary advances in proteomic techniques have changed the way we can analyze the composition, regulation, and function of protein complexes and pathways underlying altered neurobiological conditions. When combined with complementary approaches, these advances provide the contextual information for decoding large data sets into meaningful biologically adaptive processes. Neuroproteomics offers potential breakthroughs in the field of alcohol research by leading to a deeper understanding of how alcohol globally affects protein structure, function, interactions, and networks. The wealth of information gained from these advances can help pinpoint relevant biomarkers for early diagnosis and improved prognosis of alcoholism and identify future pharmacological targets for the treatment of this addiction.

Neuropsychopharmacology Reviews (2014) 39, 104-130; doi:10.1038/npp.2013.182; published online 25 September 2013
\end{abstract}

Keywords: dependence; addiction; gene expression; protein expression; protein-protein interactions; miRNA

\section{INTRODUCTION}

The harmful use of alcohol is a worldwide problem that jeopardizes individual and social development and causes disability, loss of health, and millions of deaths (World Health Organization, 2010). Of all the other substances of abuse, alcohol is by far the most harmful despite it being a legal drug (Nutt et al, 2010). Genetic, neurobiological, environmental, and psychosocial risk factors influence some individuals to develop compulsive and uncontrolled consumption of alcoholic beverages despite serious negative consequences (Koob and Le Moal, 2001; Koob, 2006; Mayfield et al, 2008; Phillips and Belknap, 2002; Potenza et al, 2011; Tabakoff et al, 2009). The molecular mechanisms underlying alcohol dependence involve different neurochemical systems and brain regions. Indeed, longterm alcohol abuse can permanently modify brain structure and function while inducing tolerance, physical dependence, craving, and other behavioral changes. Specifically, researchers have shown that long-term exposure to alcohol induces changes in microRNA (miRNA), gene, and protein expression levels in specific brain regions (Crabbe et al, 2010; Gorini et al, 2011; Nunez and Mayfield, 2012; Renthal

${ }^{*}$ Correspondence: $\operatorname{Dr}$ G Gorini, Waggoner Center for Alcohol and Addiction Research, The University of Texas at Austin, 2500 Speedway A4800 MBB1.124, Austin, TX 78712, USA, Tel: +1 512232 2487, Fax: +1512 232 2525, E-mail: gorini@utexas.edu

Received 14 March 2013; revised 2 July 2013; accepted 4 July 2013; accepted article preview online 31 July 2013 and Nestler, 2009; Wong et al, 2011). These modifications in turn mediate altered function of individual neurons and related neural circuits, which ultimately underlie behavioral abnormalities characteristic of addiction (Hyman et al, 2006; Nestler, 2000). Therefore, the identification of genes and proteins associated with the predisposition to, or development and maintenance of alcohol dependence, is crucial to shed light on molecular mechanisms underpinning addiction and to ultimately identify novel therapeutic targets for alcoholism. In the past decade, comparison studies of subcellular amounts of transcripts and proteins showed with increasing accuracy that altered mRNA expression does not completely explain changes in protein levels (Baek et al, 2008; Chen et al, 2002; Greenbaum et al, 2003; Guo et al, 2010b; Hendrickson et al, 2009; Schwanhäusser et al, 2011). As a result, the use of proteomic techniques has grown in addiction-related research because of their ability to precisely measure global dynamic modifications in proteomes (Abul-Husn and Devi, 2006; Drabik et al, 2007; Hemby and Tannu, 2009; Li and Wang, 2007; Lull et al, 2010; Marcotte et al, 2003; Plazas-Mayorca and Vrana, 2011; Wang et al, 2011). Similar to other neuropsychiatric addictive disorders, alcoholism engages a considerable collection of protein complexes and is thus suitable for proteomic investigations. In addition, the application of proteomics allows researchers to study alcohol-perturbed protein and gene regulatory networks without the need of a priori assumptions. A number of proteins potentially related to alcohol exposure and 
dependence have been reported by proteomic studies from cell cultures, animal models, and human alcoholic brain (Anni and Israel, 2002; Gorini et al, 2011; Kasinathan et al, 2004; Lovinger, 2006; Matsumoto, 2009; Neuhold et al, 2004; Torrente et al, 2012; Witzmann and Strother, 2004); such studies offer invaluable information on neurobiological mechanisms underlying the basis of addiction, on identification of proteins as diagnostic biomarkers, and on their exploitation as putative therapeutic targets for drug development. The purpose of this commentary is to provide a comprehensive summary of the alcohol-sensitive proteins identified from proteomic studies with an eye on their potential biological, diagnostic, prognostic, and therapeutic significance.

\section{ALCOHOL ABUSE AND ADDICTION}

Alcoholism is a complex-trait disorder, and molecular mechanisms and genetic influences underpinning excessive alcohol consumption are not entirely understood (Gunzerath et al, 2011). Crucial risk factors include genetic predisposition, social environment, stress, mental health, age, and gender (Foroud and Phillips, 2012; Koob and Le Moal, 2001; Mayfield et al, 2008; Phillips and Belknap, 2002, 2002; Procopio et al, 2012; Schuckit, 2009; Volkow and Li, 2005). In particular, genetic risk factors have a key role in the etiology of alcohol abuse. The amount of risk related to heritability is estimated to be between 40 and $60 \%$, as determined from family and twin studies (Schuckit, 2009).

Long-term alcohol abuse causes persistent modifications in brain function contributing to the development and expression of tolerance, symptoms of withdrawal upon removal of alcohol, and compulsive behavior focused on obtaining more alcohol. From a clinical perspective, this condition is diagnosed when such behavioral changes are evident and lead an individual to give up occupational, familial, social, and other important responsibilities. Although the treatment of alcoholism represents a central aim in public health care, only a few medications are currently approved for this disease, whereas others are still in clinical trials (see Box 1). Another limitation to treatment is the fact that pharmacogenetic studies show that the efficacy of these drugs varies across the heterogeneous clinical population of alcoholics (Addolorato et al, 2012; Anton et al, 2006; Garbutt, 2009; Heilig and Egli, 2006; Leggio and Addolorato, 2010; Volkow and Li, 2005). Therefore, an increase in effective medications for the treatment of alcohol abuse is of critical importance; drug development depends initially on the identification of novel therapeutic targets determined from preclinical research studies. Because the effects of alcohol involve complex system interactions, numerous neuropharmacological targets associated with these systems are currently under investigation, including the following: neurotransmission systems ( $\alpha$-adrenergic, dopaminergic, endocannabinoid, GABAergic, glutamatergic, nicotinic cholinergic, neuropep-
Box 1 Current Available Treatments for Alcohol-Use Disorders

Although the development of effective treatments for alcohol-use disorders
(AUDs) represents an important public health concern, only a few medications
have been approved by the US Food and Drug Administration (FDA) for the
specific treatment of AUDs. However, several drugs, approved for the treatment of
different diseases and addictive disorders, are under clinical trial for the treatment
of AUDs.
FDA-approved medications for the treatment AUDs:
Disulfiram is an acetaldehyde dehydrogenase inhibitor that causes an
unpleasant reaction when alcohol is consumed.
Acamprosate is a functional glutamatergic antagonist with neuroprotective
effects.
Naltrexone is a pan-opioid antagonist that reduces relapse rates after
abstinence.
FDA-approved medications for the treatment of other diseases, under clinical trial
for the treatment of AUDs:
$\checkmark$ Aripiprazole is a partial dopamine agonist with antidepressant properties.
Baclofen is an agonist for GABA receptors that inhibits alcohol withdrawal
symptoms and craving.
Gabapentin is a non-benzodiazepine anticonvulsant GABA analog used in the
treatment of partial seizures.
Lamotrigine is an anticonvulsant used in the treatment of epilepsy and bipolar
disorder.
$\checkmark$ Ondansetron is a serotonin 5-HT3 receptor antagonist used mainly as an
antiemetic.
Topiramate is an anticonvulsant, most recently also approved for weight loss.
tobacco products.

tide $\mathrm{Y}$, serotonergic, and substance $\mathrm{P}$ ), pathways associated with acetaldehyde-related enzymes, corticotropin-releasing factor, feeding-related peptides, neuroinflammation, and nociception, among others (Addolorato et al, 2012; Leggio and Addolorato, 2010; Spanagel, 2009). Advances in highthroughput technologies promise to accelerate the process of pinpointing therapeutic targets and offer invaluable diagnostic and screening potential for a multifaceted disease like alcoholism.

\section{Relevance of Proteomics to Alcohol Research}

The relevance of 'omic' strategies to the study of alcoholism can be better appreciated by considering the influence of similar approaches to other psychiatric, drug abuse, neurodegenerative disorders (Geschwind, 2003; Marcotte et al, 2003; Mirnics et al, 2000; Tkachev et al, 2003) and even cancer, where improved pharmacotherapies (Okutsu et al, 2002; Taxman et al, 2003; Zembutsu et al, 2002) have led to improved molecular classification of diseases (Davis and Hanash, 2006; Kemming et al, 2006; Konkimalla et al, 2007; Lea and Ling, 2008). The advances in proteomics offer distinct advantages over conventional molecular approaches when studying genes and encoded proteins perturbed by alcohol or that mediate its effects. Such a high-throughput strategy allows investigators to simultaneously survey large numbers of potential target molecules in an unbiased manner without prior knowledge of which molecules might be involved. However, proteomic efforts have so far not completely succeeded in providing exclusive, unanimous, and definitive insights, because of procedural 
drawbacks and potential interpretational pitfalls. When applied to addiction research, proteomic methods do present some technical limitations and require robust animal model selection with adequate sample size, accurate sample quality control, sample preparation and/or fractionation, rigorous statistical analysis of results, and validation of changes in protein expression using alternative methods (Abul-Husn and Devi, 2006; Li and Wang, 2007; Lull et al, 2010). Moreover, many proteomic studies analyzed whole brain tissue or relatively large brain regions because of the need of greater amounts of starting material compared with microarray experiments, which can potentially yield extensive genome coverage from single cells. As a result, proteomic findings are often less specific in terms of providing molecular snapshots of small neurocircuits with a key role in addiction. Despite the challenges intrinsic to these still emerging techniques, these methods have nonetheless changed the way genes and proteins are studied.

Proteomic techniques have evolved rapidly over the past few years, and the integration and interpretation of the huge amounts of data obtained from such studies are complicated by many factors. It has been shown that the magnitude of changes in brain gene and protein expression induced by alcohol exposure is less pronounced than in other diseases (Bull et al, 2001; Liu et al, 2006; Smith, 2002). Therefore, to avoid the possibility that individual diversity could overshadow the discrete differences underlying alcohol-related disorders, expression data for a large number of proteins should be combined and interpreted with rigorous appropriate statistical tests and bioinformatics. Advances in bioinformatics will undoubtedly simplify the interpretation of large amounts of data and pinpoint common underlying areas of biological significance. Although the methodologies are continuously evolving, proteomic strategies have already become essential tools for elucidating the molecular effects of addictive substances. In the past decade, the number of laboratories using protein expression profiling to define changes in global proteomes in cultured neurons or different brain regions of animals or humans in response to substances of abuse has been steadily growing (Bierczynska-Krzysik et al, 2006; Hemby and Tannu, 2009; Hemby, 2010; Li and Wang, 2007; Romanova et al, 2012; Song et al, 2012; Wang et al, 2011; Witzmann and Strother, 2004).

\section{PROTEOMIC STRATEGIES FOR DISCOVERY OF THERAPEUTIC TARGETS OF ALCOHOL}

Chronic alcohol exposure can induce a wide range of adaptations in brain function. Alcohol has been shown to damage neurons in multiple brain regions, leading to cognitive impairment and other abnormalities of brain function (Harper, 2009; Pfefferbaum, 2004; Sullivan and Pfefferbaum, 2005). The neuronal and behavioral adaptation of the brain to the constant presence of alcohol can lead to severe withdrawal symptoms when alcohol levels
Box 2 Post-Translational Modifications

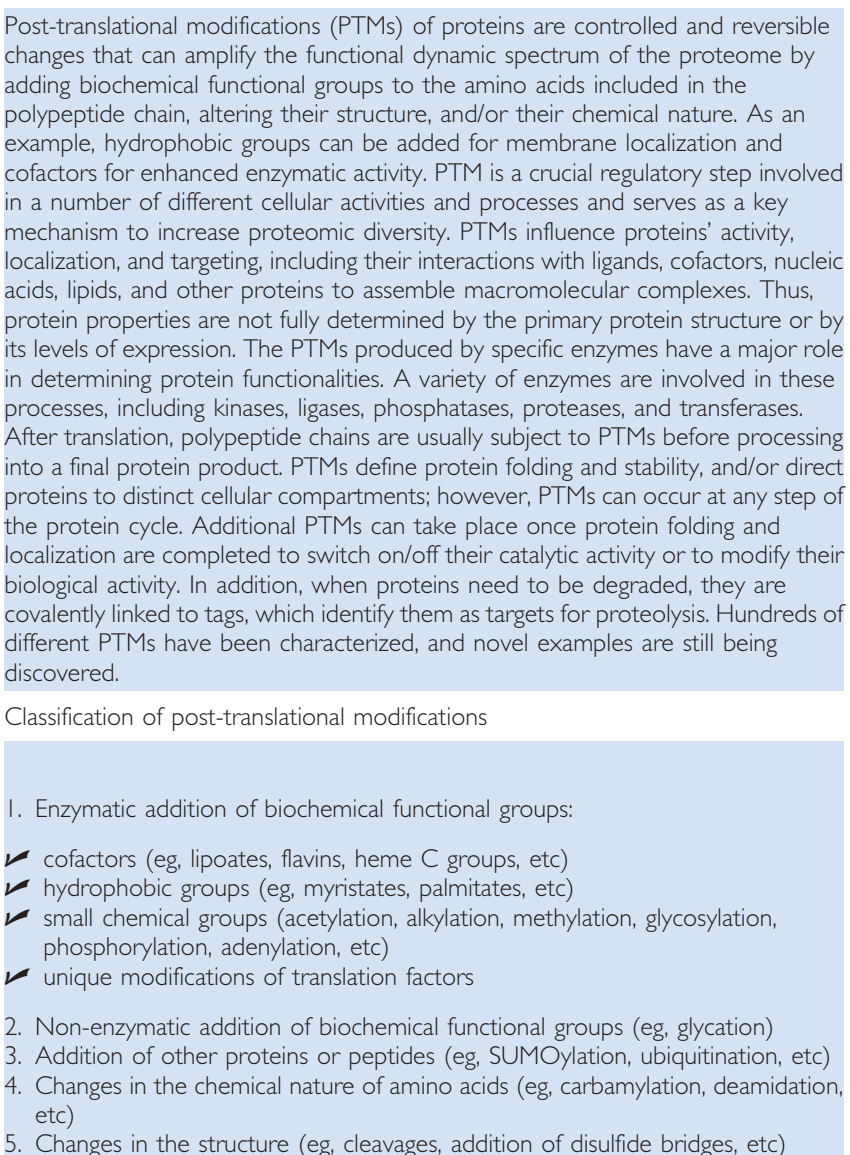

5. Changes in the structure (eg, cleavages, addition of disulfide bridges, etc)

suddenly drop. The damaging effects of alcohol on the brain as well as on other peripheral adaptive responses are mediated, at least in part, by altered gene and protein expression (Nestler, 2000, 2005).

Proteomic methods have been extensively utilized in several fields, and over the past decade investigators have gradually begun to use proteomic analyses to advance our understanding of the effects of alcohol on the brain. Compared with the genomic studies, proteomic approaches entail distinctive challenges. For example, the proteome is much larger than the genome. A large diversity in proteins results from differential gene splicing, trans-splicing, post-translational modifications (PTMs) (Box 2), and other mechanisms (Moreira et al, 2012). Although the human genome is estimated to contain 20-25 thousand protein-coding genes, the human proteome is estimated to range in the low millions (Jensen, 2004; Uhlen and Ponten, 2005). Protein expression levels exhibit different variability compared with gene expression levels (Anni and Israel, 2002), the same amount of protein is not translated from each gene, and some proteins can be expressed in distinct cell types only. In addition, many proteins are expressed only in incredibly small amounts, especially those with regulatory functions. Therefore, their identification is challenging, relative to background noise from other proteins 
simultaneously expressed in much larger amounts in the same cells or tissues.

\section{Correspondence Between Gene and Protein Expression}

Molecular modifications in gene expression levels following alcohol exposure have been reported in many alcoholrelated studies (Gorini et al, 2011). These studies are limited by the fact that genes and their encoded proteins do not necessarily follow parallel trends in their expression. It has been shown that alcohol administration produces changes in protein translation without affecting corresponding mRNA levels (Dodd and Lewohl, 1998), and fluctuations in mRNA levels do not always reflect altered protein expression (Chen et al, 2002; Greenbaum et al, 2003; Gygi et al, 1999). miRNAs have been used as tools to compare mRNA abundance and translational rates. Related studies showed that mRNA degradation accounts for about $75 \%$ of the changes observed in protein synthesis (Hendrickson et al, 2009) and that miRNAs cause a decrease in mRNA levels that can explain most of the reduction (84\%) in protein production (Guo et al, 2010b). Advances in mass spectrometry (MS) and bioinformatics have been used to estimate the absolute copy number of cell proteins to compare turnover and expression levels of mRNA and proteins. The results showed that mRNA levels account for only about $40 \%$ of the variability in protein levels (Schwanhäusser et al, 2011). As protein abundance is predominantly controlled at the level of translation, proteomic methods provide invaluable tools to detect brain modifications underlying alcohol and drug addiction.

\section{Introduction to the Technologies Currently Used in Neuroproteomic Alcohol Research}

Proteomes are encoded from thousands of genes, with a high degree of complexity and a broad dynamic range due to alternative splicing variants and PTMs. The measurement of important effector proteins is an essential component of alcohol research. The simultaneous quantitative analysis of thousands of proteins has become possible with recent advances in high-resolution MS and bioinformatics. These methodologies can provide the quantitative analysis of hundreds to thousands of proteins in complex mixtures, thus representing tools of choice for the elucidation of molecular mechanisms that underlie the neurobiology of addiction.

In the recent past, many proteomic platforms have been developed for the qualitative and quantitative analysis of protein mixtures and PTMs. Selecting a proteomic method depends on the nature of the biological question, researchers' expertise, availability of efficient MS core facilities with up-to-date instrumentation, time frame available for the experiment, and budget limits. The major limitation in proteomic technologies is the incomplete proteome coverage when analyzing complex protein samples in a single experiment. For efficient analysis, many protein fractionation methods must be implemented to simplify sample complexity and focus on subproteomes of interest. Another strategy involves the combination of complementary proteomic methods; a number of studies have shown that several proteomic methods can detect different sets of proteins and can therefore be used in parallel to achieve higher resolution of the proteome. A full review of proteomic methods is beyond the scope of this article; in Box 3, we briefly describe proteomic techniques in the past decade that have been applied to study changes in brain protein expression underlying genetic predisposition to, or induced by excessive, alcohol consumption/exposure.

\section{Proteomic Profiling Studies in Cell Cultures}

The effects of alcohol exposure on cell cultures have been studied with proteomic techniques, for example, twodimensional (2D) electrophoresis. Although studies with the intact nervous system are more relevant for elucidating mechanisms of alcohol abuse-related behaviors, the use of proteomic profiling with in vitro neuronal culture models has many advantages. The integration of protein expression studies with in vitro models of alcohol exposure can provide key insights on mechanisms of cellular signaling and toxicity.

There is increasing evidence that alcohol, as a psychoactive drug, can affect immune responses. For example, reactive oxygen species derived from the alcohol oxidation metabolic pathway induce an unfolded protein response (UPR) as a protective mechanism from the toxic effects of misfolded proteins causing endoplasmic reticulum (ER) stress. UPR in turn can alter the expression of genes involved in antioxidant defenses, inflammation, energy metabolism, protein synthesis, apoptosis, and cell cycle regulation. In a proteomic study (Boukli et al, 2010), the alterations in protein expression of human dendritic cells, treated with $0.1 \%$ alcohol for $24 \mathrm{~h}$, were investigated by $2 \mathrm{D}$ gel electrophoresis followed by liquid chromotgraphy (LC)MS and confirmed at the gene expression level by qRT-PCR. Alcohol exposure significantly changed the expression of 32 proteins compared with the control cultures. Changes in the proteome affected several components of the UPR stressinduced pathways that include chaperones, ER stress, antioxidant enzymes, proteases, alcohol dehydrogenase, cytoskeletal, and apoptosis regulating proteins. The expression of relevant UPR and antioxidant genes was also increased as evaluated by qRT-PCR analysis. The results suggest that alcohol exposure induces UPR in dendritic cells, and the authors speculate that although activation of UPR by alcohol may protect the cells from oxidation injury, it may also lead to the development of alcohol-related diseases.

As breast cancer, compared with other cancers affecting women, is associated with alcohol consumption, a related study (Lee et al, 2013) investigated the effect of alcohol exposure $(100 \mathrm{mM}$ for $48 \mathrm{~h})$ on the growth regulation in T47D breast cancer cells. The researchers used 2D electrophoresis and matrix assisted laser desorption, time of flight 
Box 3 Proteomic Approaches Used to Study the Neurobiology of Alcoholism

Proteomic approaches are sometimes described as top-down or bottom-up. Topdown approaches are used for profiling proteomes at the intact protein level to preserve biochemical characteristics and modifications of proteins. Conversely, bottom-up strategies involve analysis of peptide fragments resulting from enzymatic cleavage of proteins. These fragments are still sufficiently distinctive for the identification of the parent protein but are rarely used to provide information on the entire sequence; peptide fragments are even more effective for protein identification than intact protein level analyses. Bottom-up approaches need to be combined with modern chromatographic or electrophoretic technologies to simplify highly complex peptide mixtures. Methods for protein identification include mass measurements for a set of peptide fragments from the parent protein (peptide mass fingerprinting) or analysis of information derived from the fragmentation process of these peptides.

Two-dimensional electrophoresis (2-DE) is a consolidated technique, which separates mixtures of proteins in two dimensions (electric charge and mass). It can resolve isoforms due to PTMs and splice variants. When combined with MS and advanced image analysis software, 2-DE can deliver important information on protein expression. However, this technology is limited by its relatively small dynamic range (extremely acidic, basic, or hydrophobic proteins are difficult to detect, as well as those with high or small molecular weights and those present in low abundance). For these reasons, 2D differential in-gel electrophoresis (2D-DIGE) represents a superior technique, given its more precise, reproducible, and sensitive approach. The use of fluorescent dye labeling allows loading of multiple samples on the same gel, eliminating gel-to-gel variation. The major disadvantages of 2D-DIGE are the high cost for reagents, instruments, and software. Also, individual spots can contain two or more proteins that differ only minimally in their isoelectric point and mass, which can lead to complications in the subsequent analyses. Furthermore, to minimize the influence of variable labeling efficiency, the dyes should be appropriately swapped to exclude any related bias. Overall, 2D-DIGE will remain a valuable complementary method for proteome characterization in the near future (Rogowska-Wrzesinska et al, 20।3). Given that current MS-based techniques typically sample only a fraction of all the proteins present in a sample, only a fraction of all identified proteins can be reliably quantified (Bantscheff et al, 2007).

The basic concept of non-gel-based methods, termed shotgun proteomic analyses, is the identification of proteins in complex mixtures derived from tissues or cells by combining various fractionation techniques, like liquid chromatography (LC), directly online with MS analysis. As a sample extract can easily contain severa thousand proteins at variable concentrations, this approach has become possible only through the development of automated processes. Multidimensional protein identification technology (MudPit or LC LC MS/MS) (Wu et al, 2003) refers to the use of two LC columns to separate complex mixtures of proteins before applying MS.

The two main MS-combined strategies currently used for protein quantitation are generally referred to as labeling and label-free methods. Labeling techniques use isotopic labels as a reference for relative or absolute quantitation. These labels can be introduced into samples in vivo by metabolic labeling (Wu et al, 2004) or SILAC (Ong et al, 2002), and in vitro by iTRAQ (Ross et al, 2004) or TMT tags (Dayon et al, 2008). In particular, iTRAQ is a comprehensive and efficient method for proteomic quantification that provides multiplex capability and can identify lowexpressed proteins with high confidence in complex samples. Nevertheless, iTRAQ requires sample fractionation, high sample abundance, high costs for reagents, instruments, and software, and involves variable labeling efficiency, complex sample preparation procedures, and inconsistent ratios from complex samples. Thus, investigators are progressively switching to label-free quantitative proteomic methods given their lower costs, higher dynamic range of quantification, and faster results (Mann, 2009; Patel et al, 2009). MS-based, label-free quantitative proteomics embraces two general categories (Zhu et al, 20 l0): ion abundancebased measurements (peptide peak areas or peak heights) and spectral counting of identified proteins after MS/MS analysis. Compared with labeling approaches, these methods have to be carefully controlled given the possible errors caused by run-torun variations when performing LC and MS. However, rapid advances in label-free methods have improved the reliability and accuracy of protein expression

measurement in complex biological samples (Coombs, 20I I). Finally, quantitative methods for targeted analysis of protein-specific peptides in complex protein samples include selected reaction monitoring (SRM) (Shi et al, 20I2) and multiple reaction monitoring (Sherwood et al, 2009). SRM can identify and quantify specific peptides with very high sensitivity and reproducibility.

(MALDI-ToF) MS to evaluate changes in protein expression in addition to various other techniques. Results showed 14 downregulated and 8 upregulated proteins. The increased expression of c-ros receptor tyrosine kinase (ROS1) was confirmed by western blotting. This study demonstrated the relationship between alcohol and cell proliferation associated with activation of the MAPK pathway by ROS1 protein.

\section{Proteomic Studies in Zebrafish}

Zebrafish exhibit strain differences in terms of sensitivity and tolerance to alcohol and are sensitive to pharmacological concentrations of alcohol (Dlugos and Rabin, 2003). A proteomic study (Damodaran et al, 2006) investigated the effects of 4 weeks of chronic alcohol treatment $(0.5 \%(\mathrm{v} / \mathrm{v}))$ on the brain of Danio rerio using a 2D-differential in-gel electrophoresis (2D-DIGE) system combined with MALDIToF MS. The results reported 13 differentially regulated proteins in the supernatant fraction and 18 in the pellet fraction. Voltage-dependent anion channels, heat-shock protein 70 (HSP70), and $\alpha$-subunit of Go (GNAO1) were upregulated following alcohol exposure. This study reported some novel protein targets as well as substantiated some previously identified alcohol targets.

\section{Proteomic Studies in Mice}

Several mouse models for increased alcohol consumption have been investigated using different proteomic techniques. Many researchers have used proteomic profiling to identify line- and/or strain-specific changes in protein expression patterns after alcohol administration. In several mouse studies, protein expression levels were compared between B6 and D2 strains (see Box 4), and transgenic and knockout mice have also been utilized. Different brain regions and different methods of alcohol administration were studied.

In a 2-DE proteomic-based study (Park et al, 2004), whole brain tissue obtained from two inbred mouse strains, C57BL/6J (B6, alcohol-preferring) and DBA/2J (D2, alcoholavoiding), were analyzed to identify alcohol-responsive proteins. Both strains were subjected to oral administration of a single dose of alcohol $(1.5 \mathrm{~g} / \mathrm{kg})$. Over 50 proteins showed differential expression patterns between the two strains. The authors first classified those proteins according to their frequency of repetition and rate of changed expression profiles over time, then combined the proteomic data with predicted protein interactions to distinguish proteins with respect to their potential function and shared pathways. Finally, they concluded that the different responses to alcohol between $\mathrm{B} 6$ and D2 strains may be due to differences in response rates and interactions of different variants of the alcohol-responsive protein family.

Some researchers used proteomics to investigate the anxiolytic properties of alcohol (Sikela et al, 2006). For example, they used a transgenic mouse model for anxiety (adenylyl cyclase 7, ADCY7) based on the observation that a predisposition to anxiety may promote alcohol intake as a form of negative reinforcement, and on the evidence that a polymorphism in the $A D C Y 7$ gene is associated with risk for 
Box 4 Animal Models Used in Alcohol-Related Proteomic Studies

The identification of molecular determinants of excessive alcohol consumption remains a major challenge. Proteomic studies have provided valuable new insights into protein regulation in genetically complex diseases such as alcoholism. Over the past decade, protein expression profiling has been used to identify alcoholresponsive proteins and associated pathways in different animal models of alcoholism. Rodents are the prime organisms of choice for modeling human diseases, and the genetically based propensity of some rats and mice to prefer and others to avoid alcohol has provided the basis for alcohol behavioral neuroscience preclinical research (Bell et al, 2012; Crabbe et al, 2010; Reilly et al, 2012).

A common approach in alcohol research involves the identification of differences in gene/protein expression between strains of animals selectively bred for divergent alcohol-related phenotypes. These studies are particularly challenging in terms of statistical power to identify small but reliable differences in brain gene/protein expression. Indeed, the magnitude of these alcohol-induced changes is small if compared with widespread alterations characteristic of other substance abuse disorders. Access to large databases of expression data and meta-analytic approaches can mitigate these obstacles (Bhave et al, 2007; Mulligan et al, 2006 (meta-analysis of several microarray datasets to study alcohol preference phenotypes)). The studies reported in this review aim to identify constitutive

differences in protein expression among diverse inbred strains or selectively bred alcohol-naive animals or to identify the effects of different alcohol intake/

administration paradigms on protein expression.

anxiety in humans. First, synaptosomal preparations from whole brains of naive wild-type and ADCY7 transgenic mice were analyzed using Multidimensional Protein Identification Technology (MudPIT) (Wu et al, 2003), as part of a larger set of experiments combining in silico, genomic, and proteomic strategies. Five of the identified proteins mapped to a quantitative trait locus (QTL) for anxiety previously reported by the same group. To estimate the quantitative differences in protein levels between the same mice in an unbiased manner, the researchers used metabolic labeling with ${ }^{15} \mathrm{~N}$ to generate (as an internal standard) labeled brain tissue, which was then cofractionated as synaptosomes using either unlabeled tissue from wild-type or transgenic mice. Mixed synaptosomal samples resulting from each fractionation were analyzed using MudPIT, and the relative abundance ratios of wild-type/standard and transgenic/ standard were measured and compared (Wu et al, 2004). With their multifaceted approach, the researchers quantified about 150 proteins, with 26 proteins showing significant differences between the two mouse strains. The results demonstrated predominant protein upregulation in transgenic mice compared with wild type, and specifically identified proteins related to calcium transport and signaling and proteins involved in anxiety-related behavior. Overall, this study showed the effective use of global, unbiased strategies to identify alcohol candidate genes and proteins associated with anxiety-related behaviors, pathways, and QTLs.

Another group (Sari et al, 2010) used a label-free quantitative proteomic analysis to investigate the effect of ethanol on central nervous system development in fetal brains of prenatally alcohol-treated C57BL/6 mice. Moderate prenatal alcohol exposure results in brain defects at different stages of development, interferes with the growth of the central nervous system, and induces neurodegeneration through cellular apoptosis. Pregnant mice were exposed from the 7th to the 13th embryonic day with either a $25 \%$ ethanol derived calorie diet or pair-fed liquid diet.
Fetal brains were subjected to chromatography combined with an LC-MS/MS system. Prenatal alcohol exposure induced significant downregulation of several important mitochondrial enzymes, cytoskeletal, nuclear, and cytosolic proteins such as Bcl-2, 14-3-3, calmodulin, prohibitin, and doublecortin. These findings highlighted impairments in energy generation, growth and development, cellular signaling, and neuronal migration as possible mechanisms underlying the effects of prenatal alcohol exposure during early embryonic stages.

Mice lacking type 1 equilibrative nucleoside transporter $\left(\mathrm{ENT}^{-/-}\right)$represent a model for increased alcohol consumption. The increased alcohol preference in these mice involves increased glutamate neurotransmission in the nucleus accumbens (NAcc). This model has been studied using isobaric tags for relative and absolute quantitation (iTRAQ) proteomics, combined with other techniques, to elucidate the compensatory mechanisms following deletion of ENT1 and their effect on glutamate signaling in the NAcc (Nam et al, 2011). The results showed that out of 533 identified proteins, only five signaling proteins were significantly changed in the NAcc of $\mathrm{ENT}^{-1-}$ mice compared with ENT1 ${ }^{+/+}$controls: neurogranin, calmodulin, and phosphatidylethanolamine-binding protein 1 were upregulated, whereas cAMP-dependent protein kinase catalytic $\beta$-subunit and sodium-dependent glutamate/aspartate transporter 2 were downregulated. As neurogranin and calmodulin are essential components of $N$-methyl-Daspartate receptor (NMDAR)-mediated signaling, the authors propose that the deletion of ENT1 results in altered NMDAR signaling, which provides a molecular basis for the ethanol-preferring behavior of ENT1 ${ }^{-1-}$ mice.

A recent study (Gorini et al, 2013a) used 2D-DIGE to analyze cerebral cortices and midbrains from C57BL/6J mice subjected to a chronic intermittent ethanol (CIE), twobottle choice $(2 \mathrm{BC})$ paradigm, which induces heavy drinking and represents one of the best available animal models for alcohol dependence (Lopez and Becker, 2005). The CIE-2BC protocol included ethanol vapor-exposed mice (dependent) and air-exposed mice (non-dependent), which both had access to alcohol, plus a third group of alcoholnaive mice. CIE-2BC induced significant protein expression changes in ethanol vapor-exposed mice compared with their air-exposed matched controls and with alcohol-naïve mice. Multiple protein isoforms showed region-specific differential regulation as a result of PTMs. This study reported molecular changes in endocytic- and energy-related pathways. The results were supported by a coexpression analysis of the proteomic data, with specific proteins involved, such as dynamin-1 and its isoforms, mostly upregulated in alcohol-dependent mice. The protein changes identified in this comprehensive analysis could have a key role in the escalation of ethanol consumption associated with dependence and may in part relate to relapse vulnerability since the paradigm used included two 3-day 'respite' periods, 2 weeks of withdrawal, and brains were collected 3 days after the last drinking episode. 


\section{Proteomic Studies in Rats}

Proteomic approaches involving rat models of alcohol consumption have examined direct strain-dependent differences in protein expression in response to alcohol (see Box 4). For example, the proteomes of relevant brain regions from inbred alcohol-preferring (iP) and -non-preferring (iNP) rats have been compared in three studies using a variety of techniques.

The first study (Witzmann et al, 2003) analyzed protein expression differences in two brain regions, amygdala (Amy) and NAcc of alcohol-naïve iP and iNP rats, using 2D electrophoresis and MALDI-ToF MS. Among the significant differentially expressed proteins, the levels of expression were generally lower in the $\mathrm{P}$ rats compared with the NP rats in both regions, and the largest differences were detected for cellular retinoic acid-binding protein 1 and a calmodulin-dependent protein kinase, both involved in cellular signaling pathways. Additional changes were identified in the NAcc, where proteins involved in the following functions were reported: metabolism, cytoskeletal and intracellular protein transport, molecular chaperoning, cellular signaling pathways, synaptic function, reduction of oxidative stress, and growth/differentiation. This study provided the first proteomic evidence showing that selective breeding for disparate alcohol drinking behaviors can induce innate modifications in protein levels with the potential to impact neuronal function.

Another study (Bell et al, 2006) investigated the effect of continuous $v s$ binge-like alcohol drinking on protein expression levels in the same regions (NAcc and Amy) with the same techniques, but using only the iP rats. Three alcohol groups were compared: ethanol-naive (EN), continuous 24/7 free-choice access to ethanol (CE), and multiple scheduled access (MSA). The paradigm lasted over 6 weeks, and rats were killed $10 \mathrm{~h}$ after ethanol removal. Analysis of drinking patterns revealed a significant alcohol deprivation effect in MSA group, which represents a transient increase in alcohol intake occurring in laboratory animals after a period of alcohol deprivation (MartinFardon and Weiss, 2013; Spanagel, 2005). The results showed region-specific changes induced by alcohol that were dependent on the type of alcohol paradigm. Notably, changes specifically associated with MSA (Tpm1,Tpm3, Enog2, Ywhaz, Prkar2b, Vdac1 in the NAcc and chaperonin containing TCP1 subunit $3 \gamma$, heat-shock protein $70 \mathrm{kDa}$, serum albumin precursor, and ubiquitin-conjugating enzyme E2N in the Amy) may be related to withdrawal and relapse liability. MSA induced greater changes in protein levels in the NAcc, whereas CE had greater effects on the Amy. In general, alcohol consumption had modulatory effects on proteins associated with the cytoskeleton, cellular stress response, membrane transport, metabolism and energy production, and neurotransmission. As only two of the differentially expressed proteins were common between the NAcc and Amy, the authors concluded that the diverse pattern of protein expression changes observed between the two regions might reflect correspondent differences in neuroanatomical and functional characteristics associated with ethanol self-administration and possibly withdrawal.

In a third proteomic study, the same group (McBride et al, 2009) used a label-free, LC-MS-based protein quantification method (Higgs et al, 2005) to determine the effects of repeated systemic administration of a moderate dose $(1 \mathrm{~g} / \mathrm{kg})$ of ethanol on protein levels in the NAcc shell of inbred alcohol-preferring (P), alcohol-non-preferring (NP), and non-inbred Wistar (W) rats. The shell portion of the NAcc was selected due to its involvement in mediating reinforcement processes, and using such a selective area also increases the resolution of the analysis. Rats received five daily injections with either saline or ethanol (Smith and Weiss, 1999) and experienced $24 \mathrm{~h}$ of withdrawal after the last injection. Ethanol administration modified the expression patterns of a larger number of proteins in NP compared to both $\mathrm{P}$ and $\mathrm{W}$ rats. Few of the changes observed with ethanol treatment for NP rats were observed for $\mathrm{P}$ and $\mathrm{W}$ rats. Many of the changes occurred in calcium-calmodulin signaling systems, G-protein signaling systems, synaptic structure, and histones. Approximately half of the changes observed in the NAcc shell of $\mathrm{P}$ rats were also observed for $\mathrm{W}$ rats. Overall, this study showed a unique response to ethanol within the NAcc shell of NP rats compared to $\mathrm{P}$ and $\mathrm{W}$ rats; this unique response may reflect changes in neuronal function in this brain area that could contribute to the low alcohol drinking behavior and/or higher sensitivity to alcohol exhibited by NP rats.

Alcohol abuse during adolescence represents a major health concern. During adolescence the brain continues to undergo critical developmental changes, and alcohol abuse can induce particularly adverse neural and cognitive changes. Adolescents are typically more susceptible to alcohol-induced memory impairment, and hippocampal damage has a crucial role in these memory dysfunctions (Pitel et al, 2007). Accordingly, adolescent rats have been shown to display greater impairment in spatial memory acquisition and longer memory performance deficits than adult rats under the influence of alcohol (Sircar and Sircar, 2005; White et al, 2000). Thus, several research groups are focusing their studies on age-specific effects of chronic alcohol abuse. For example, a 2D-electrophoresis based proteomic study (Hargreaves et al, 2009) has investigated the effects of chronic alcohol intake on the protein levels in the hippocampus of adolescent compared with adult wistar rats. After 4 weeks of access to alcohol (beer), rats were subjected to an additional 2-week period of alcohol withdrawal. Beer consumption resulted in modest changes in the adult group, with only two proteins upregulated compared with controls. Conversely, alcohol exposure induced widespread changes in the hippocampus of adolescent rats relative to their controls, involving proteins related to glycolysis, glutamate metabolism, neurodegeneration, synaptic function, and cytoskeletal structure. These results highlighted the vulnerability of adolescent brain to lasting effects induced by alcohol exposure and suggested putative 
mechanisms by which alcohol abuse and binge drinking can induce damage in the developing hippocampus, leading to lasting cognitive and emotional disturbances.

More recently, another group (Maldonado-Devincci et al, 2012) proposed a different methodology for assessing the effects of chronic ethanol exposure during adolescence in rats. This approach incorporates either a label-free or a chemical tagging method using iTRAQ, and can complement other proteomics-based studies such as 2D gel electrophoresis described earlier, providing an unbiased global assessment of age-specific expression of neuroproteins induced by alcohol.

The studies mentioned above utilized relatively short alcohol paradigms. Rat models using only short periods of alcohol exposure might not adequately represent the specific neuroadaptations in motivation-related brain pathways that contribute to the long-term process of addiction, where alcohol consumption becomes an established compulsive routine that is resistant to reprogramming. This discrepancy was assessed by a recent study (Kashem et al, 2012) in which proteome changes were examined after 8 months of moderate daily alcohol consumption obtained with the 'beer model'. The whole striatum was chosen for this study, because of its contribution to decision making, emotional and motivational aspects of behavior, and major role in addiction-related neuroadaptations. Proteomic 2-DE analysis showed that a total of 28 striatal proteins were significantly altered in the beer-drinking rats relative to controls. The most salient changes were in proteins associated with dopamine biosynthesis and related intracellular signaling, energy metabolism, and oxidative stress. These results showed how daily alcohol consumption at relatively modest levels causes major biochemical adaptations in dopaminergic signaling pathways in the rat striatal proteome.

\section{Proteomic Studies in Human Post-Mortem Brain}

Global proteomic approaches on human post-mortem brain have been used to study several different alcohol-sensitive brain regions from both uncomplicated and hepatic cirrhosis-complicated human alcoholics.

Several considerations need to be made when applying proteomic profiling to human post-mortem brain. The postmortem interval, agonal state, and tissue $\mathrm{pH}$ are important parameters that can influence the quality of the analysis. In addition, comparisons across proteomic studies performed from different laboratories are complicated by differences in tissue harvesting, proteomic platforms, sample processing, use of labeling, and data analysis procedures. Brain regional differences may be related to differences in case selection criteria such as age, gender, alcohol drinking history, etc. In addition, the effects of comorbidities (polydrug use, poor diet, smoking, etc) can diminish and potentially compromise the reliability of results. Availability of accurate clinical information is therefore critical for experimental design and for the evaluation of individual differences across cases.
The most studied region of human brain is the prefrontal cortex (PFC), an area important for judgment, decision making and other cognitive functions (Godefroy and Rousseaux, 1997; Rahman et al, 1999; Ratti et al, 2002). This region is also associated with neurocircuitry involved with mediating reward, which influences the development and expression of alcohol tolerance and dependence (Vetulani, 2001).

Analyses of post-mortem brain of long-term alcohol abusers have reported neuronal loss in gray matter and loss of white matter volume (Harper, 2009; Kril and Harper, 1989; Pfefferbaum, 2004; Sullivan and Pfefferbaum, 2005). These effects are less pronounced in motor, temporal, or cingulate cortices, suggesting that alcohol-induced brain damage is likely brain region selective. The impact of concomitant liver cirrhosis on the brain proteome has also been tested in different brain regions of cirrhotic $v s$ noncirrhotic alcoholics. Cirrhosis, the widespread disruption of liver structure with fibrosis and regenerative nodules, represents a common comorbid condition resulting from long-term alcohol abuse.

The first application of proteomics in human alcoholic brain compared pooled autopsy samples from four longterm, well-characterized chronic alcoholics to four healthy control subjects using two dimensional electrophoresis (Lewohl et al, 2004). This study reported about 180 differentially expressed proteins in the superior frontal cortex, with predominant downregulation (139 down- vs 35 upregulated proteins) observed in alcoholics. Using both MALDI-MS and MS-MS, the authors were able to identify 63 proteins, including enzymes, ion channels, and signalingrelated proteins.

Proteomics was also used to investigate the effects of alcohol abuse in the dorsolateral PFC, which includes Brodmann area 9, with white (wBA9) (Alexander-Kaufman et al, 2006, 2007a) and gray matter (gBA9) (AlexanderKaufman et al, 2007a). The dorsolateral PFC is connected to many brain regions involved in cognitive functions by reciprocal projections and is subject to significant shrinkage in alcoholics, particularly the white matter. Autopsy samples obtained from alcoholics with and without cirrhosis and non-alcoholics were compared using 2D electrophoresis combined with MALDI-ToF MS analyses. In both wBA9 and gBA9 regions, transketolase and pyruvate dehydrogenase E1 $\beta$-subunit were differentially expressed in both groups of alcoholics, suggesting alterations in the thiamine-dependent cascade. Furthermore, the levels of many metabolism-related enzymes were differentially regulated, in particular those related to energy transduction (glycolysis, Krebs cycle), suggesting energy deficit, loss of viability, and cell death in the dorsolateral PFC of alcoholics.

The cerebellar vermis (CV) of uncomplicated and cirrhotic alcoholics was also analyzed with the same techniques (Alexander-Kaufman et al, 2007b). The CV receives somatic sensory input and is associated with bodily posture and locomotion. Owing to its connections with PFC, the cerebellum is indirectly involved in cognitive functions, 
and the CV is susceptible to general shrinkage or atrophy in alcoholics, with loss of Purkinje cells and reduced dendritic arborization. As found in the dorsolateral PFC, transketolase and pyruvate dehydrogenase E1 $\beta$-subunit were also differentially regulated in both groups of alcoholics, indicating that changes in vitamin B1-dependent and energy metabolism-dependent enzyme levels could contribute to $\mathrm{CV}$ damage in alcoholic brain. In addition, the proteomic analysis revealed some unique changes in the $\mathrm{CV}$ of cirrhotic alcoholics, suggesting specific effects on $\mathrm{CV}$ protein expression resulting from liver dysfunction.

A concomitant study from the same group focused on the proteomic analysis of the hippocampus (MatsudaMatsumoto et al, 2007), which has crucial roles in cognitive processes, memory, and spatial navigation. Autopsy samples from uncomplicated alcoholics were compared with normal, non-alcoholic controls using the same 2D gel approach combined with MS identification. This study reports 18 out of 20 identified proteins as downregulated in alcoholics, and while some of them were identified in other brain regions mentioned above, hippocampal proteomic analysis showed unique, significant changes in the level of glutamine synthetase expression, an enzyme predominantly located in astrocytes that can detoxify hepatic products like ammonia.

Further studies investigated the corpus callosum (CC) in detail by distinct analyses of its posterior part (splenium), its anterior part (genu), and the truncus (body) among complicated vs uncomplicated alcoholics and controls (Kashem et al, 2007, 2008, 2009). The CC connects the left and right cerebral hemispheres, is the largest white matter structure in the brain, and regulates various cognitive functions. This region is also subject to volume reduction following excessive alcohol consumption, resulting in cognitive dysfunctions. The comparative analysis of CC subregions showed region- and group-specific chronic alcohol-induced alterations of various biochemical pathways. Several proteins involved in different metabolic pathways such as lipid peroxidation, oxidative stress, and apoptosis showed specific differential expression in the CC body. Thiamine/energy biosynthesis enzymes were differentially regulated in the genu, whereas glutamate carboxypeptidase (GCP1) was identified in both splenium and genu of complicated alcoholics only.

Two proteomic studies on alcoholic human brain analyzed synaptosomal preparations from superior frontal gyrus (SFG). This area is part of the PFC, which controls executive functions; it is generally considered severely affected by alcoholism, and is susceptible to alcoholism-induced neuronal loss. In an effort to unravel the mechanism underpinning synaptic disorders in alcoholism, the first study (Etheridge et al, 2009) compared SFG with occipital cortex (OC), a brain region that does not lose gray matter in response to alcoholism and does not exhibit obvious functional changes; OC was therefore considered by the authors as an alcohol-spared brain region in comparison with the alcohol-susceptible SFG. Synaptosomes from chronic alcoholics and non-alcoholic controls were compared using 2D electrophoresis and MS, and the results showed that alcoholism induced changes in the synaptic proteome in both the SFG and the OC compared with controls. This study confirmed a number of proteins previously linked to alcoholism as well as pinpointing novel alcoholism-affected proteins, owing to the specific fractionation used. Unexpectedly, the majority of proteins altered were in the OC rather than in the SFG. The identified proteins are involved in vesicle transport, metabolism, folding and trafficking, and signal transduction. The changes relative to vesicle transport and cytoskeleton proteins suggested alterations in synaptic transmission pathways and may contribute to the neurodegenerative effects of alcohol and to its general disruption of cognitive function.

In their second study (Etheridge et al, 2011), the group above used the same techniques to analyze synaptosomes from the SFG of controls and from uncomplicated and cirrhotic alcoholics. Cirrhotic alcoholics showed changes in protein expression levels compared with both controls and non-comorbid alcoholics, likely caused by differences in disease severity between the subgroups of alcoholics. This disease-state specific regulation was accompanied with significant differences between post-translationally modified protein isoforms that are known to be involved in basal energy metabolism, synaptic vesicle recycling, and chaperoning.

All of the studies above indicate that high-throughput neuroproteomic approaches can potentially dissect the mechanisms of complex brain disorders and suggest that chronic alcohol consumption can directly alter the levels of several important brain proteins. Nevertheless, some major observations should be pointed out. First, even though there is a partial correspondence in the differentially expressed proteins across multiple alcohol-sensitive brain regions and distinct fractionation methods, from the studies described above it appears evident that every region shows specific patterns of protein expression. Although these corresponding changes confirm the relevance of pathways previously described as general reaction mechanisms to prolonged alcohol abuse, distinct region-specific alterations may be induced as exclusive mechanisms of neurobiological adaptation. In addition, the human studies are complicated by gaps in the knowledge of the subjects' history, and the observed protein changes could result from other unknown concomitant conditions. Studies comparing complicated cirrhotic alcoholics with non-comorbid alcoholics show how hepatic-induced factors affect protein expression profiles. This suggests that improving liver function in alcoholics could potentially prevent further brain damage (Matsumoto, 2009). Finally, the investigation of specific changes in isoform regulation due to diverse PTMs in different disease states can provide novel insight into the mechanisms involved in cerebral damage in alcoholics. Understanding the exact role that these widespread changes have in cellular regulation during alcohol dependence continues to be a challenge for addiction biologists. 


\section{Proteins and Pathways Associated with Alcohol Exposure}

Proteomic techniques applied to alcohol research can shed light on multiple molecular targets and pathways, improving our understanding of the complex consequences of alcohol on brain function. From the 22 published alcoholrelated proteomic studies reviewed above, we collected 460 unique proteins reported to be associated with alcohol exposure. Twenty-eight proteins have been identified in at least four of these studies and are listed in Table 1. Although this might appear as little concordance, it is noteworthy that the studies described above differ in methodologies, statistical analysis of results (and number of proteins reported), species, brain region, sample preparation, and alcohol protocol used. On a different viewpoint, 26 of 348 proteins $(7.5 \%)$ were reported by at least 4 out of 17 studies $(\sim 25 \%)$. Creatine kinase B-type, which has a central role in energy transduction in the brain, was identified by nine independent proteomic investigations and therefore represents one of the most important alcohol targets. Similarly, changes in dihydropyrimidinase-like 2, enolase, heat-shock $70 \mathrm{kDa}$ protein 8 , and lactate dehydrogenase B protein levels were described by eight different alcohol-related proteomic publications. Fifty-four well-consolidated, alcohol-sensitive proteins, reported by at least three of these studies, were analyzed for functional category enrichment. Owing to the large diversity in the functions of the proteins annotated, we used Ingenuity Pathway Analysis (IPA) (Ingenuity Systems, www.ingenuity.com) to more clearly highlight the major enriched biological pathways underlying alcohol's effects. Interestingly, the top networks associated with the collected proteomic signatures include neurological disease, immunological-inflammatory disease, carbohydrate metabolism, and cell morphology. In addition cell death, cellular assembly, organization, function, and maintenance, as well as nucleic acid metabolism, are the main molecular/cellular functions affected. Some of the representative biochemical pathways enriched among these proteins are glycolysis/ gluconeogenesis, mitochondrial dysfunction, and protein ubiquitination. Signal-transduction pathways related to neuronal functions include Parkinson's signaling, clathrinmediated endocytosis signaling, 14-3-3-mediated signaling, p70S6K signaling, and Huntington's disease signaling (Table 2). These pathways are involved in important neuronal functions and have also been associated with general molecular mechanisms of drug addiction.

Proteomic approaches represent powerful tools for the investigation and identification of biological processes underlying alcohol dependence. Nevertheless, owing to the limitations of the methods utilized to date, not all the proteins associated with alcohol exposure have been identified by proteomic technologies. Similar to what has been found for other proteomic studies of addictive disorders (Wang et al, 2011), the majority of identified proteins related to alcohol abuse belong to a relatively small number of functional categories (Figure 1). This is consistent with the observation that some genetic influences may not be specific for alcohol-use disorders, but likely reflect a general vulnerability for polysubstance abuse (Gorini et al, 2011; Mayfield et al, 2008; Nestler, 2005). Other proteins such as neurotransmitter receptors, well known to have critical roles in the development of alcohol dependence, are under-represented in proteomic studies despite the fact that their genes have been associated with alcohol exposure at both mRNA and protein levels. This can be explained by the small dynamic range of the proteomic techniques used in the above studies. Advances in sample preparation and separation techniques will improve the sensitivity and power of proteomic analyses.

\section{Interaction Proteomics Approaches}

Protein-protein interactions (PPIs) have a central role in virtually every process of a living cell. Proteins interact with other proteins by assembling into macromolecular complexes that are part of dynamic PPI networks of high complexity; these networks coordinate the variety of processes that impact cellular function, and their topology, with the association and dissociation of protein complexes, has broad biological importance. Biologists rely on interaction data in several ways: layering PPIs onto other networks, exploring how sets of proteins are interconnected, classifying proteins with the most interacting partners, and uncovering new biological functions by the superposition of biophysical and functional data. For example, we used an online PPI database (STRING, http:// string-db.org) to explore the interaction network of alcoholsensitive proteins described by proteomic studies and listed in Table 1. Network analysis revealed that the most connected interacting partner protein is polyubiquitin-C (Figure 2), thus confirming the involvement of ubiquitination pathways suggested by IPA functional analysis. PPIs participate in various physiological processes and are essential for neurotransmission. The release of neurotransmitter molecules responsible for signaling among neurons involves regulated PPIs (Brodin et al, 2000), and ion channels or neurotransmitter transporters in synaptic membranes are regulated by complex PPIs (Deken et al, 2000; Garner et al, 2000; Maiya et al, 2007; Muth et al, 1998; Staub and Rotin, 1997; Sung et al, 2005). Thus, identification and characterization of PPIs can not only advance our understanding of the processes that occur during normal neurotransmission but also highlight cell function adaptations because of the presence of alcohol. Importantly, this could provide the basis for new therapeutic approaches since newly identified PPIs may represent novel targets for drug development. This strategy has emerged as an important subfield in medication development (Arkin and Wells, 2004; Dev, 2004; Reilly et al, 2009), although PPIs do not always have detectable effects. Three-dimensional structural information can be used to predict PPIs (Zhang et al, 2012). There is also growing evidence that select clusters of functionally related gene expression profiles 
TABLE 1 Proteins Reported as Differentially Expressed by At Least Four Alcohol-Related Proteomic Studies

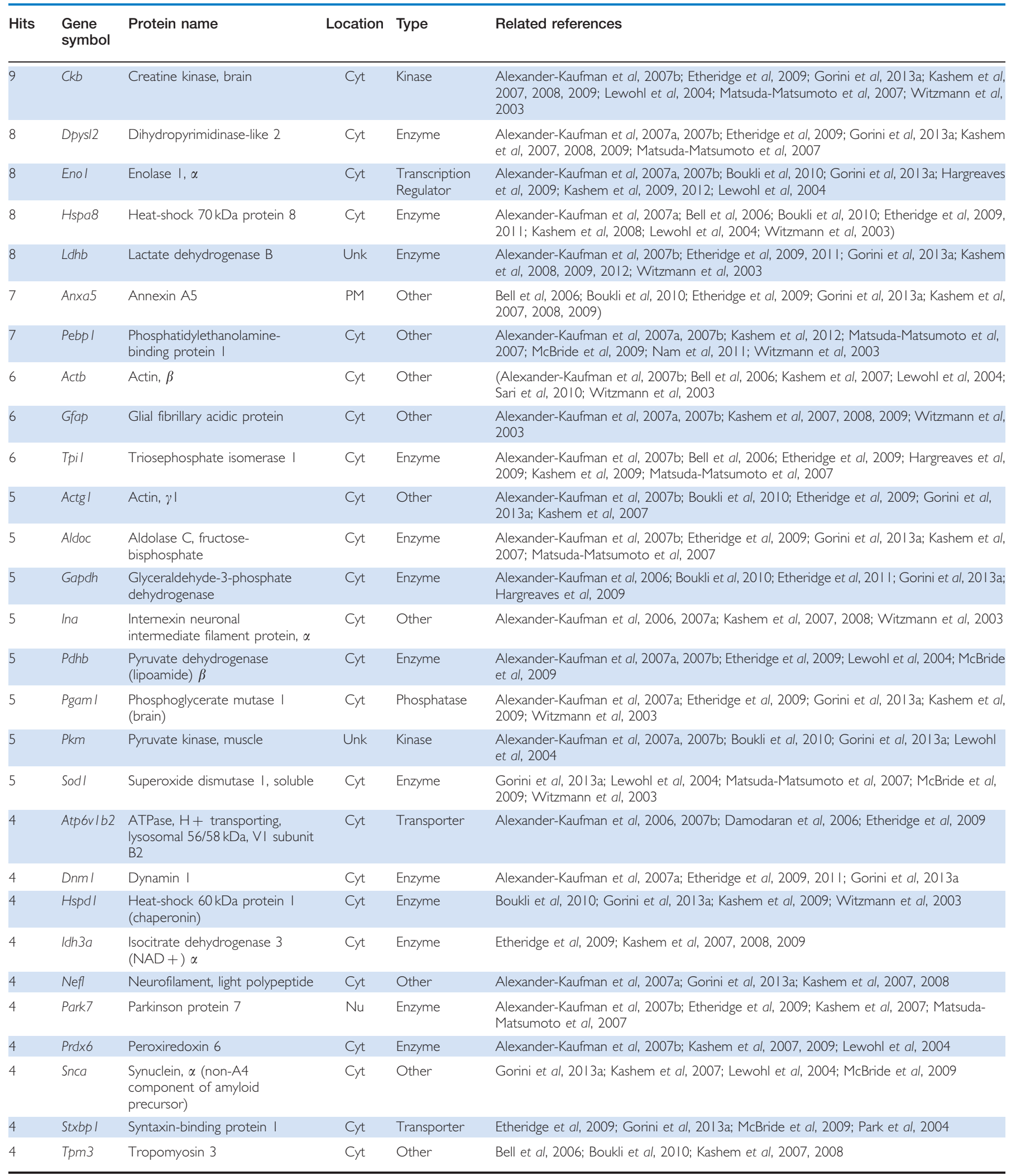

Abbreviations: Cyt, cytoplasm; Nu, nucleus; PM, plasma membrane; Unk, unknown.

Consolidated alcohol-sensitive proteins, described as differentially expressed by at least four alcohol-related proteomic studies. The number of related references referring to each protein is shown under the column Hits. Gene symbol, full name, location, and function are also listed for each protein. 
TABLE 2 Ingenuity Canonical Pathways Enriched in Genes Encoding Proteins Associated with Alcohol Exposure

\begin{tabular}{llll}
\hline Ingenuity canonical pathways & P-value & FDR & Molecules \\
\hline Glycolysis I & $6.41 \mathrm{E}-13$ & $8.65 \mathrm{E}-1 \mathrm{I}$ & PGKI, TPII, ENOI, PGAMI, PKM, GAPDH, ENO2, ALDOC \\
Gluconeogenesis I & $6.46 \mathrm{E}-09$ & $4.36 \mathrm{E}-07$ & PGKI, ENOI, PGAMI, GAPDH, ENO2, ALDOC \\
Parkinson's signaling & $1.64 \mathrm{E}-05$ & $7.37 \mathrm{E}-04$ & UCHLI, PARK7, SNCA \\
Clathrin-mediated endocytosis signaling & $2.77 \mathrm{E}-05$ & $9.35 \mathrm{E}-04$ & HSPA8, DNMI, ALB, APOAI, ACTB, ACTGI \\
I4-3-3-Mediated signaling & $3.68 \mathrm{E}-05$ & $9.93 \mathrm{E}-04$ & YWHAG, PDIA3, YWHAZ, GFAP, SNCA \\
p70S6K signaling & $6.58 \mathrm{E}-04$ & $1.24 \mathrm{E}-02$ & YWHAG, PDIA3, EEF2, YWHAZ \\
Huntington's disease signaling & $7.33 \mathrm{E}-04$ & $1.24 \mathrm{E}-02$ & GNBI, HSPA8, DNMI, HSPA2, SNCA \\
Protein ubiquitination pathway & $1.35 \mathrm{E}-03$ & $1.65 \mathrm{E}-02$ & UCHLI, HSPA8, HSPDI, HSPA2, HSPAI2A \\
Sucrose degradation V & $1.46 \mathrm{E}-03$ & $1.65 \mathrm{E}-02$ & TPII, ALDOC \\
Mitochondrial dysfunction & $1.46 \mathrm{E}-03$ & $1.65 \mathrm{E}-02$ & PARK7, ATP5AI, UQCRCI, SNCA \\
Caveolar-mediated endocytosis signaling & $1.80 \mathrm{E}-03$ & $1.87 \mathrm{E}-02$ & ALB, ACTB, ACTGI \\
\hline
\end{tabular}

Consolidated alcohol-sensitive proteins, described as differentially expressed by at least three alcohol-related proteomic studies, were analyzed with ingenuity pathway analysis (IPA). A significantly enriched pathway is defined as one with $P<0.05$ and a false discovery ratio (FDR) $<0.05$. The $P$-value is calculated by Fisher's exact test right-tailed. The FDR is calculated by the method of Benjamini and Hochberg (1995).

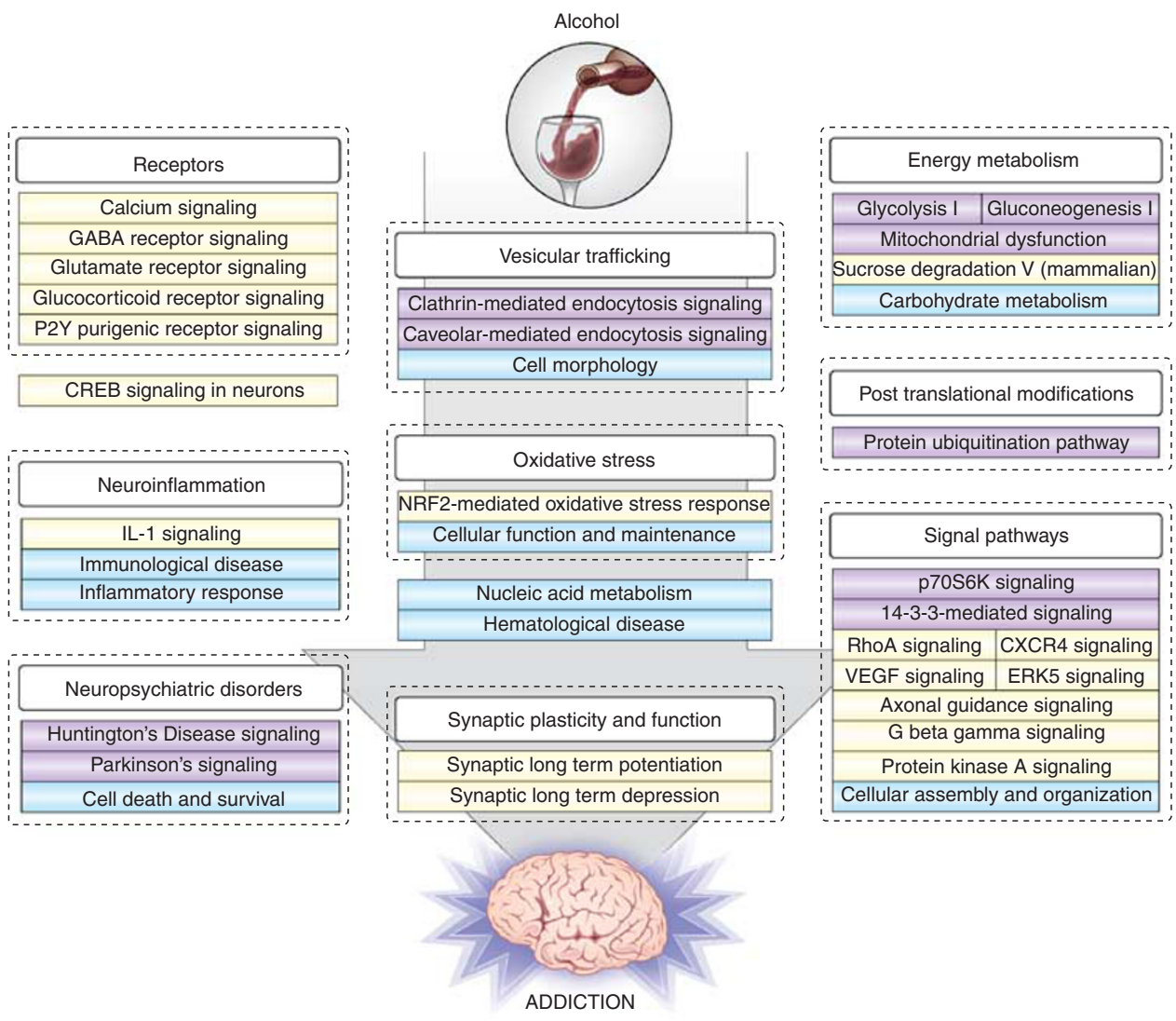

Figure 1. Neurobiological effects of alcohol suggested by proteomic studies. To elucidate the complex effects of excessive alcohol consumption on neurons, regulated proteins reported by proteomic studies were analyzed with Ingenuity Pathway Analysis (IPA). Alcohol modulates multiple pathways, affects several biological processes, and likely activates the molecular machinery responsible for preserving cellular homeostasis. Related direct or indirect mechanisms can in turn alter several signaling pathways (including those involved in receptor-mediated neurotransmission), disturb energy metabolism, produce oxidative stress, perturb vesicular trafficking, affect cell fate, and ultimately induce permanent plastic neuronal modifications responsible for addictive behavior. White boxes describe major biological processes; blue boxes indicate enriched Ingenuity molecular and cellular functions; purple boxes display enriched ingenuity canonical pathways resulting from core analysis of 54 proteins differentially expressed in at least three independent alcohol-related proteomic studies; yellow boxes show the pathways resulting from a similar analysis involving 460 proteins collectively reported by 22 proteomic studies. Significantly enriched pathways are defined as the ones with $P<0.05$ and a false discovery ratio (FDR) $<0.05$. The $P$-value is calculated by Fisher's exact test right-tailed. The FDR is calculated by the method of Benjamini and Hochberg (1995).

identified by array studies can be used to predict meaningful networks of interacting proteins (Bhardwaj and Lu, 2005; Lu et al, 2005; Ramani et al, 2005). For example, gene expression studies have shown that alcohol alters the expression pattern of many genes required for normal synaptic function (Gorini et al, 2011; Mayfield et al, 2008). 


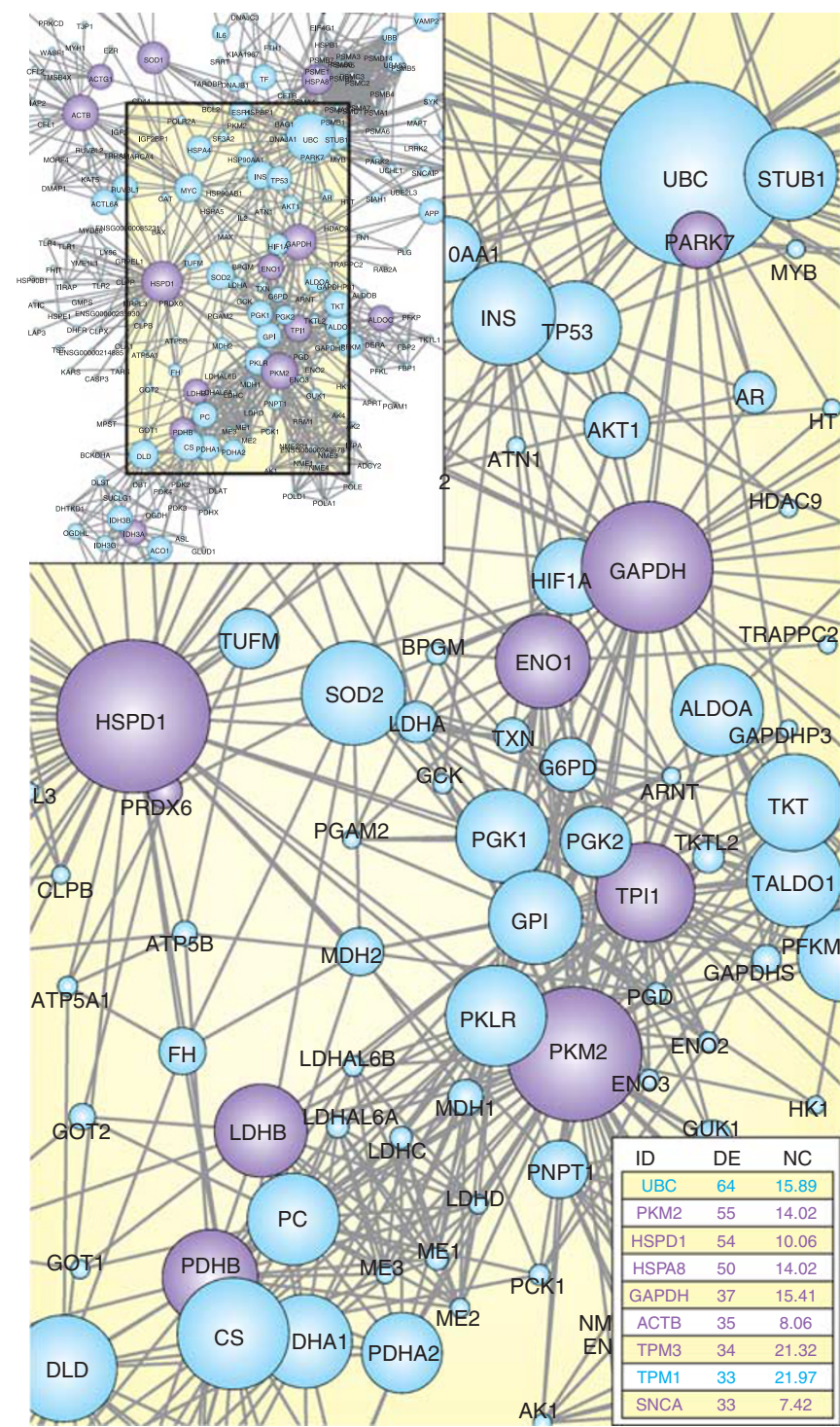

Figure 2. Protein interaction network involving alcohol-sensitive proteins described by proteomic studies. The figure offers an example of how PPI data from different sources could be integrated with protein expression profiles by weaving molecular interaction networks. These networks provide an easy visualization (by zooming in/out, rotating, using layouts to group nodes, etc) on how sets of candidate proteins are interconnected. Plus, precise analysis of interconnectedness can be calculated, which is particularly useful in the case of large networks. The most connected node is polyubiquitin-C (UBC), a protein involved in ubiquitination pathways. As in case of other bioinformatics tools, data obtained should be verified with additional experiments and researchers should carefully filter out interactions that have not been validated, to avoid possible overinterpretation of related biological meaning. In this case, Ingenuity Pathway Analysis (IPA) functional analysis and previous literature confirm the perturbation of protein ubiquitination pathways in alcoholism. The network was generated as follows. Interacting partners from proteins listed in Table 1 were obtained from STRING 9.05 database (http://stringdb.org, settings: homo sapiens, highest confidence 0.900 , and no more than 50 interactors). Data were imported in Cytoscape 2.8.3 and a network was generated using the plugin NetworkAnalyzer 2.7. Purple circles indicate the original proteins identified by at least four proteomic studies, and node degree is mapped to node size. DE, number of directed edges; NC, neighborhood connectivity.
These genes encode proteins important for multiple synaptic events, such as motor proteins involved in trafficking and targeting of synaptic proteins, scaffolding proteins, and proteins involved in neurotransmitter vesicle transport and targeting. Therefore, it is plausible that excessive alcohol consumption alters protein complexes required for normal synaptic transmission, and related PPIs may therefore be important sites for the development of new medications to treat complex diseases such as alcoholism.

There is limited knowledge about the direct effects of alcohol on synaptic proteins in the context of PPIs; furthermore, although there is interest in identifying the accessory PPIs of synaptic proteins, relatively few have been identified and confirmed to date (Abul-Husn et al, 2009; Barth and Volknandt, 2011; Khanna et al, 2007; Klemmer et al, 2009; Li et al, 2010; Lu et al, 2007).

One of these studies used interaction proteomics to examine synaptic protein complexes isolated from cortical membranes of alcohol-naïve C57BL/6J mice (Gorini et al, 2010). Immunoprecipitation experiments were performed to identify PPIs using synaptic proteins as baits. The following proteins encoded by alcohol-responsive genes were used as baits: syntaxin-1A (Worst et al, 2005), synaptosome-associated protein 25 (Liu et al, 2007), vesicle-associated membrane protein 2 (Worst et al, 2005), dynamin-1 (Saito et al, 2002), and the BK channel (Pietrzykowski et al, 2008). Subsequent immunoblots and mass spectrometric analyses confirmed known and identified novel, interacting protein partners in the co-immunoprecipitates. Remarkably, the BK channel complex included many alcohol-sensitive proteins, including dynamin-1, syntaxin-1A, syntaxin-binding protein 1, heat-shock $70 \mathrm{kDa}$ protein 8 , and members of the kinesin superfamily. Given that the BK channel is a well-established alcohol target, important in behavioral and molecular tolerance (Treistman and Martin, 2009), and many of its interacting partners are encoded by genes also known to be perturbed by alcohol, future studies will no doubt continue to investigate this protein interaction network.

Other important proteomic studies have focused on neurotransmitter systems known to be influenced by alcohol. For example, Husi et al (2000) characterized the protein complex of the NMDA receptor using interaction proteomics. This study identified 77 different proteins as interacting partners in the NMDA receptor complex, with a various range of functions such as binding glutamate and initiating intracellular signaling processes.

Dopaminergic neurons are also affected by alcohol, and the activity of the dopamine transporter (DAT) is regulated by multiple signaling mechanisms, at least some of which are likely to involve PPIs. An interaction proteomics approach was used to identify the DAT interacting protein partners (Maiya et al, 2007). Using immunoprecipitation followed by gel electrophoresis for the separation of the coprecipitate, individual partner proteins isolated from the gel were identified by MS analysis. The DAT was associated with 20 proteins with diverse cellular functions that could 
be classified as signaling proteins, trafficking proteins, cell adhesion molecules, ion channels, cytoskeletal proteins, metabolic enzymes, and extracellular matrix-associated proteins. Interestingly, DAT was found to specifically interact with the voltage-gated potassium channel Kv2.1 and with the synaptic proteins synapsin-1 and dynamin-1, involved in regulating neurotransmitter release and recycling. An in silico analysis was also performed to evaluate the biological significance of these interacting proteins as a group. The correlation between the expression levels of the genes encoding the various interacting proteins was greater than would be predicted by chance alone, suggesting common regulatory mechanisms.

Few studies have shown direct evidence of the effects of alcohol exposure on PPIs. One of these studies (HongBrown et al, 2010) examined the effect of ethanol on the interaction complex of the mammalian target of rapamycin (mTOR), which is a key regulator of cell growth and proliferation and plays an important role in regulating protein synthesis in response to alcohol. The mTOR interacts with several proteins to form the mTOR complex 1 (mTORC1) consisting of: regulatory-associated protein of mTOR (raptor), TORC subunit LST8 (mLST8/G $\beta \mathrm{L}$ ), and proline-rich Akt substrate 40 (PRAS40). Incubation of C2C12 myocytes with ethanol (100 mM, 24 h) caused changes in PPIs in the mTORC1 complex. Immunoprecipitations followed by immunoblots showed that ethanol enhanced the binding of raptor and PRAS40 with mTOR and these changes occurred in concert with increased binding of the cytosolic protein 14-3-3 to raptor, whereas the PRAS40 and 14-3-3 interaction was not affected. Taken together with other experimental evidence, the results from this study suggest a possible mechanism for the inhibitory effects of ethanol on mTOR kinase activity and protein synthesis in myocytes.

Prenatal exposure to ethanol could result in fetal alcohol spectrum disorder (FASD), which induces long-term cognitive, behavioral, and developmental defects and is often accompanied by neuronal cell death that in turn reduces brain volume. Clusterin is a glycoprotein with various roles (antiapoptotic, proapoptotic, and chaperone) that is upregulated in some neurodegenerative diseases (Nuutinen et al, 2009; Přikrylová Vranová et al, 2010). Cell death induced by ethanol in the developing mouse brain requires B-cell lymphoma 2-associated X protein (Bax), a proapoptotic protein (Young et al, 2003); clusterin normally interacts with Bax, thus inhibiting apoptosis (Trougakos et al, 2009). An interesting study (Kim et al, 2012) investigated mechanisms of ethanol-induced cell death in the developing brain of the rat, one of the most commonly used animal models of FASD. This study involved an interaction proteomic approach to test the effect of ethanol on clusterin's PPIs. Seven-day-old rats were subcutaneously injected with $20 \%$ ethanol ( $3 \mathrm{~g} / \mathrm{kg}$, administered two times). Following acute ethanol treatment, clusterin upregulation was detected in the cerebral cortex. Co-immunoprecipitation experiments followed by immunoblotting showed the interaction of nuclear clusterin with Bax and with an antiapoptotic protein of the same family, B-cell lymphomaextra large (Bcl-XL). Clusterin was co-immunoprecipitated with Bcl-XL and vice versa in the cerebral cortices from ethanol-treated rats but not from control rats. Furthermore, the co-immunoprecipitation of Bcl-XL and Bax was reduced by $36 \%$ in ethanol-treated rats compared with controls, implying that upregulated clusterin sequestered Bcl-XL, releasing Bax and thus mediating apoptosis. This study concluded that nuclear clusterin has a proapoptotic role in ethanol-induced cell death in the developing brain, providing new insights on the development of FASD.

A comprehensive network of ethanol-related candidate genes has been constructed and analyzed (Guo et al, 2010a). The authors collected many large-scale data sets for alcohol dependence and ethanol response in human, rat, mouse, Drosophila, and Caenorhabditis elegans, and deposited them in a web-based gene resource database (ethanolrelated gene resource, ERGR; bioinfo.mc.vanderbilt.edu/ ERGR/). On the basis of evidence for multiple genes among these data sets, they prioritized 57 ethanol-related candidate genes. Gene ontology term-enrichment tests and pathway analysis revealed that these candidate genes were highly enriched in alcohol dependence and highly expressed in the brain or liver. In addition, their PPI network analysis examined connections of the same candidate genes in the human interactome, from which they extracted a subnetwork of 106 molecules (nodes) and 158 links (edges). Among these nodes, 56 were new genes, not comprised in the original list of candidate genes. Among the new genes, 25 were linked to alcohol according to the ERGR database. In this subnetwork, they ultimately identified six genes that were highly connected to the proteins encoded by ethanolrelated genes based on evidence provided by the ERGR database; these genes were tyrosine-protein kinase Fyn, vinculin, Von Hippel-Lindau disease tumor suppressor, calnexin, promelanin-concentrating hormone, and sintaxin-1A. This study is a prime example of how publically available PPI databases can be used to integrate experimental data from different sources with consolidated interactome maps to study the molecular mechanisms of alcohol dependence. Similar approaches could be applied to study the features of other putative, candidate genes from alternative phenotypes.

In summary, examining complex diseases in terms of PPIs, rather than individual genes and proteins, could help elucidate the underlying neurobiology of alcoholism and other addictive disorders. Select clusters of genes can predict meaningful networks of interacting proteins that are sensitive to the effects of alcohol and may represent potential sites important for medication development. Results from PPI studies should still be confirmed by different methodologies and/or identified across multiple species, and researchers should filter out interactions that have not been validated. Methods designed to block or disrupt PPIs are potentially promising for elucidating their functional roles. MS-based strategies allow for absolute 
quantification of proteins and provide accurate measurement of protein complex levels and detection of even small changes within PPI networks (Marcilla and Albar, 2013; Wepf et al, 2009). Complete reference interactome maps of PPIs will not only provide biological insight into cellular organizational principles but also generate novel hypotheses and advance basic experimental research in various disciplines. Importantly, elucidation of novel mechanisms by which alcohol regulates complexes of interacting proteins will enable significant contributions to the field of addiction research.

\section{Structural Proteomics to Study Alcohol-Sensitive Ion Channels}

Several families of brain proteins that are sensitive to modulation by ethanol have been defined in the past few years, and this allows a molecular and even atomic level analysis of the alcohol binding sites on these target proteins (Harris et al, 2008). Prominent among these targets are ion channels, which catalyze neurochemical reactions and form the supportive structural environment for neurotransmission to occur. For example, important alcohol-sensitive ion channels include potassium channels (especially GIRK), ligand-gated ion channels (including glutamate, especially NMDA), and the pentameric ligand-gated ion channels (pLGIC) (Howard et al, 2011). There has been considerable progress in defining sites of alcohol actions on several pLGIC, including $\gamma$-aminobutyric acid type A $\left(\mathrm{GABA}_{\mathrm{A}}\right)$, glycine (Gly), and nicotinic receptors (Blednov et al, 2011; Borghese and Harris, 2012; Borghese et al, 2003; McCracken et al, 2010, 2013; Murail et al, 2012; Sauguet et al, 2013). Importantly, genes for five of the pLGIC receptor subunits (GlyR $\alpha 3, \mathrm{GABA}_{\mathrm{A}} \mathrm{R} \gamma 1, \rho 1,2$, and $\alpha 2$ ) have been linked with human alcohol dependence (Gorini et al, 2011; Han et al, 2012; Ittiwut et al, 2012; Mayfield et al, 2008; Xuei et al, 2010), but very little is known about specific roles of these subunits in alcohol actions. Indeed, as noted above, conventional gel-based and shotgun proteomic techniques have limited capability in detecting low abundance integral membrane proteins like native ion channels, because of various technical problems including solubilization, enzymatic digestion and recovery, and separation of hydrophobic peptides from transmembrane (TM) domains. However, a recent study described a method for the deep amino-acid sequencing of native brain $\mathrm{GABA}_{\mathrm{A}} \mathrm{Rs}$ using high-resolution MS (Chen et al, 2012b). Starting from a small sample amount, the researchers were able to obtain high peptide coverage for $12 \mathrm{GABA}_{\mathrm{A}} \mathrm{R}$ subunits. A label-free quantitative MS analysis was also applied to three separate brain samples to determine the relative abundances of 11 $\mathrm{GABA}_{\mathrm{A}} \mathrm{R}$ subunits. In another study (Vogel et al, 2009), MALDI-ToF MS was used to identify tryptic fragments corresponding to both native disulfide bonds (superfamilyspecific Cys-loop and GlyR-specific bond) in the extracellular domain (ECD) of GlyR $\alpha 1$. This evidence confirmed the disulfide bond formation for both pairs of cysteines in the ECD of GlyR $\alpha 1$, which had been predicted by homology modeling.

Understanding high-resolution 3D structures of alcoholsensitive ion channels can simplify the design and development of new structure-based drugs. Indeed, such structural studies by X-ray crystallography and nuclear magnetic resonance spectroscopy have a crucial role in pharmaceutical research (Kim and Doyle, 2010). For example, a critical advance in our understanding of the molecular interaction of alcohol on protein comes from explorations of the bacterial pLGIC GLIC, which provided the first X-ray crystal structure of ethanol bound to a pLGIC (Sauguet et al, 2013). Emerging structural evidence indicates that ethanol occupies water-filled cavities in proteins, particularly between $\alpha$-helices, and this requires hydrogen bonding with the hydroxyl group of the alcohol and usually a serine or threonine in the protein as well as weak hydrophobic interactions (Cheng et al, 2008; Harris et al, 2008; Sauguet et al, 2013). However, crystallographic and spectroscopic methods are complex, lack dynamicity, require high protein concentrations, and can be challenging depending on the size of proteins and/or their inability to form crystals. Therefore, there is a strong interest in alternative techniques for the detection of small proteins at low concentrations. Structural proteomics is the application of protein chemistry and modern mass spectrometric approaches to important biological questions such as the characterization of protein structures and complexes, and the in-depth identification of PPIs. Importantly, the use of structural proteomics can help to decipher the detailed structure of interfaces between proteins and the interactions between proteins and ligands (Serpa et al, 2012). Therefore, the application of such techniques can provide valuable information on putative druggable targets. Structural proteomics uses different complementary methods in combination, including chemical protein modification, chemical crosslinking, covalent labeling, limited proteolysis, photoaffinity, and hydrogen/deuterium exchange (Kaur and Chance, 2012), all followed by mass spectrometric analysis. These MS-based technologies are emerging as new tools to study the highly dynamic process of ligand binding to ion channels, and have been utilized to shed light on the interactions between a protein and its ligand in absence of high-resolution crystallography data on the protein of interest. As such approaches cannot provide 3D structural information, they are usually combined with theoretical computations, modeling, and other biochemical methods. For example, limited proteolysis coupled to MS on reconstituted GlyR $\alpha 1$ homopentamers identified proteolytic cleavages within proposed TM domains, postulated to fold as bilayer-spanning $\alpha$-helices, and also identified unexpected membrane-associated regions in the $\mathrm{N}$-terminal domain (Leite et al, 2000). These proteolysis data were later integrated with additional biochemical evidences to construct novel topological models (Leite and Cascio, 2001). Further studies showed homology modeling and molecular dynamics simulations to construct models of the 
homopentameric $\alpha 1$-subunits of the GlyR TM domain to compare the binding of ethanol molecules to the channel in open and closed states (Cheng et al, 2008).

In another example, structural proteomic techniques combining chemical crosslinking and MS have recently been applied to the analysis of human P2X1 receptors expressed in HEK293 cells, providing insight into phosphorylation, modeling, and highlighting the importance of conformational change for channel activation (Roberts et al, 2012). Similarly, a hybrid structural approach was used to analyze ligand binding by the human 5-HT4, G-proteincoupled receptor for serotonin (Padayatti et al, 2013).

In the past decade, structural proteomic techniques have been increasingly used to overcome the restrictions inherent to traditional biophysical methods. In the next future, structural proteomic experimental data, integrated with computational modeling, will provide more specific evidences and reliable results that will be progressively used to support new drug design for the treatment of brain diseases.

\section{Proteomics to Study miRNA Regulation of Gene Expression}

The majority of the RNA in a cell does not code for proteins but is non-coding regulatory RNA that orchestrates the function of the cell. miRNAs are small, non-coding oligonucleotides involved in post-transcriptional regulation of gene expression. They are considered as key regulators of a broad spectrum of cellular functions and may thus have a role in many of the widespread genomic changes induced by chronic alcohol consumption. Recent studies have revealed that miRNAs have critical roles in regulating diverse biological processes such as neuronal differentiation, developmental timing, synapse function, and neurogenesis (Le et al, 2009; Papagiannakopoulos and Kosik, 2009; Shen and Temple, 2009). With regard to alcoholism, miR-9 was found to promote splice variations in the mRNA coding for the pore-forming $\alpha$-subunit of the BK channel, a largeconductance calcium- and voltage-activated potassium channel (Pietrzykowski et al, 2008). Alcohol exposure caused an increase in miR-9 expression, which then results in a rapid degradation of one splice variant of the $\alpha$-subunit, causing reorganization of transcripts to form an alcoholresistant $\mathrm{BK}$ channel.

Mature miRNAs regulate biological processes by associating with the RNA interference silencing complex to induce translational inhibition and/or degrade target mRNA transcripts. Although a major challenge, identification of miRNA targets is crucial for understanding the biological roles of miRNAs. Target genes are defined by short sequences in their $3^{\prime}$ untranslated regions that are complementary to a given miRNA, and although bioinformatic tools have improved the unbiased prediction of miRNA binding sites, different algorithms produce divergent results with high false-positive rates. Experimental evidence showed that each individual miRNA may downregulate mRNA levels, but multiple miRNAs can also work together on an individual mRNA to alter its protein output (Nunez and Mayfield, 2012; Wu et al, 2010).

As miRNAs may regulate their targets at the translational level without affecting mRNA levels (Bhattacharyya et al, 2006; Filipowicz et al, 2008; Pillai et al, 2005), proteomic techniques are being increasingly used to understand miRNA biology. MS-based proteomics has the power to identify several core components of the canonical miRNA processing pathway and the PTMs involved in relative regulatory mechanisms. In addition, quantitative proteomic approaches are emerging as tools for the identification of genuine miRNA targets and to understand the contribution of translational repression by allowing direct determination of changes in protein expression. The measurement of mRNA levels is not ideal for the identification of miRNA targets and should be carefully used to draw conclusions about the proteome from analysis of the transcriptome for several reasons. First, mRNA and protein expression levels do not necessarily correlate (Chen et al, 2002; Griffin et al, 2002; Gygi et al, 1999; Vogel and Marcotte, 2012). Second, the simultaneous quantification of absolute mRNA and protein abundance has demonstrated discrepancies between half-lives of mRNAs and proteins (Schwanhäusser et al, 2011). Third, even the efficiency of miRNA-mediated gene silencing can be reduced by PTMs in Argonaute/RISC complex, suggesting that the simple presence of miRNA does not necessarily decrease protein production (Huang et al, 2013; Leung et al, 2011). Therefore, the use of MS-based proteomic techniques allows more in-depth investigations of the effects of miRNAs on the proteome. Current quantitative proteomic technologies like 2D-DIGE, iTRAQ, and SILAC have advantages and limitations but can be combined to reveal the full spectrum of miRNA targets. As growing evidence suggests that alcohol exposure changes miRNA expression profiles (Pietrzykowski et al, 2008; Miranda et al, 2010; Lewohl et al, 2011; Gorini et al, 2013b), future studies are expected to increasingly utilize proteomics to investigate how specific alcohol-sensitive miRNA can affect their targets at the translational level by accurately measuring protein levels under different conditions.

\section{Systems Biology and Integration of Proteomics with Complementary Approaches}

Alcohol abuse is a complex-trait disorder involving a number of pathways and inducing negative effects on multiple tissues. At the molecular level, the effects of alcohol are in part due to changes in DNA, RNA, miRNAs, proteins, and metabolites, whereas at the systems level, alcohol affects many organs, biochemical or signaling pathways, and other biological processes. Genetic factors that influence the risk for alcoholism originate from multiple genes, but the contribution of each gene may be quite small (Gorini et al, 2011; Mayfield et al, 2008; Phillips and Belknap, 2002).

Even though microarrays have improved our comprehension of complex cellular function, their reliance on hybridization kinetics results in several technical limitations 
(ie, knowledge of sequences probed, cross-hybridization, narrow dynamic range of signal). New methodologies, collectively termed next-generation sequencing, are free of the limitations inherent to microarrays. Sequencing the genome (DNA-Seq), the transcriptome (RNA-Seq), or the miRNome (miRNA-Seq) allows the detection of the entire population of RNA molecules in a cell or living tissue, thus providing information on gene structure, alternative splicing events, expressed single-nucleotide polymorphism (SNPs) (Mane et al, 2009; Tang et al, 2009; Walter et al, 2009), and transcript size, while also quantifying the absolute abundance of genes, with greater sensitivity and dynamic range than the competing microarray technology (Mortazavi et al, 2008). Nevertheless, it is evident that approaches to the study of gene regulation purely based on gene sequence would not be sufficient to explain alcoholinduced pathogenesis. Detailed whole genome information can be combined with other experimental, clinical, and/or phenotypic data to provide increased understanding of basic biological processes and a more integrated view of cellular function and regulatory networks.

There is general agreement that proteomic and transcriptomic studies deliver different albeit complementary information about gene regulation. Although the genome can be comprehensively arrayed, proteomic approaches can offer incomplete information on protein expression, PPIs, and PTMs that genomics cannot yet provide. Over the past decade, alcohol research has being continuously reshaped by increasingly sophisticated genetic tools. Selected lines, recombinant inbred strains, linkage scan, association studies, QTLs, microarray expression, SNP maps, and other tools have been used to extensively dissect alcohol dependence in humans and ethanol response in animal models. As a result, a number of databases with alcohol-related chromosome regions and candidate genes are available for diverse model organisms as well as for Homo sapiens. With such blooming of resources, one may wonder whether and how much these massive databases are converging and/or overlapping with proteomic-based findings. Comparing different databases is not always appropriate, because of diverse experimental designs, protocols, cutoffs, and procedures that could potentially bias any tentative of data synthesis. For example, a comparison of microarray studies should take account of distinct platforms (ie, chip versions), brain regions and/or species, with related differences in the background of assessed genes. In addition, it is possible that a number of matches among different data sets would occur by chance, although some extent of the overlapping genes/proteins should represent true positives when their statistical significance is high. Furthermore, the candidate genes identified can often differ in their direction and magnitude of change across studies. On the other hand, correspondence among data sets and previous alcohol-related gene/ protein expression work adds support to and strengthens the results from combined proteomic studies, helping with the interpretation of massive lists and offering a molecular 'zoom' function that can direct the focus to promising candidate molecules.

A number of proteins described in the alcohol-related proteomic studies reviewed here are encoded by genes reported to be differentially expressed following excessive alcohol consumption or dependence in different species (Gorini et al, 2011). As an example, the ERGR database described above (Guo et al, 2010a) provides data integration and candidate gene selection based on multiple data sets and organisms. When comparing their top 57 consolidate genes with the 28 genes listed in Table 1, only Gfap and Snca are common. However, all the genes in Table 1 have been previously reported as related to alcohol consumption, dependence, or genetic predisposition by individual studies listed in the ERGR database or by more recent ones (Mulligan et al, 2011; Ponomarev et al, 2012).

Rather than detecting all the relevant players involved in a biological process, it is likely that every individual expression study would identify distinct complementary subsets of biologically relevant genes/protein along with some false positives and with at least partial overlap across different studies. Therefore, a more practical way to compare and combine findings from multiple sources in a meaningful way implicates the analysis of pathways involved.

Systems biology is a relatively new scientific discipline, which aims to investigate complex biological processes by integrating data from different sources and using mathematical modeling to predict functions of biological systems (Aderem, 2005; Auffray et al, 2003; Kirschner, 2005; Liu, 2005; Westerhoff and Palsson, 2004). A fundamental concept in system biology is represented by functional 'modules', which are the building blocks of a biological system or process (ie, different species of interacting molecules within a cell). These modules are evolutionary conserved, interact with other molecules, and have discrete functions that arise from interactions among their components (ie, proteins, DNA, RNA, miRNAs, and smaller molecules), although these functions cannot be predicted by studying the properties of the isolated components. Modules are not fixed structures; their components can belong to different modules at the same time and they are also interconnected. The interactions of these interconnected modules in turn generate a higher layer of functions at another biological level (Guo and Zakhari, 2008). Modules are organized in hierarchical structures to form subsystems and systems. A biological system can consist of many interconnected modules that operate synergistically to execute the functions of a biological process. Organisms have developed evolutionary mechanisms to keep their biological systems functionally stable (Hartwell et al, 1999).

Single-discipline approaches are limited as they can only offer a fragmented view of a very complex picture. This highlights the advantage of systems approaches where we can focus on the more complex modules as opposed to individual genes. Moreover, it is possible that some effects of alcohol may be caused or accompanied by changes in coregulation that are invisible to single gene-, protein-, or 
miRNA-based analyses. Integrative approaches are thus essential in providing a global picture of the disturbances leading to alcohol addiction or related disorders. As an example, weighted gene coexpression network analysis (WGCNA) is a bioinformatics tool for the study of coexpression patterns from high-throughput data (Langfelder and Horvath, 2008; Zhang and Horvath, 2005). The correlation values between genes indicate expression level similarities or differences, and WGCNA analysis can identify modules of interconnected genes showing overrepresented patterns of coexpression. These modules can be treated as single units and related to external information used as a trait (ie, alcohol phenotypes) via simple measures (ie, correlation). This method was recently applied to the identification of epigenetic modifications in human alcoholic brain (Ponomarev et al, 2012) and to miRNA and proteomic data from a mouse model of alcohol dependence (Gorini et al, 2013b) (see below).

The application of comprehensive, integrative approaches will define the future of alcohol research (Rodd et al, 2007; Tabakoff et al, 2009; Tapocik et al, 2013) and promises to be fruitful in elucidating the mechanisms underlying alcohol addiction. Genetic and biological studies in animal models or post-mortem human brain, with epidemiological and clinical surveys on human subjects, should be integrated with genomic data. Current technologies have the potential to dissect the effects of alcohol exposure on DNA (genome, epigenome), RNA (transcriptome), protein (proteome), metabolites (metabolome), and glycans (glycome) to generate meaningful amounts of data (Guo and Zakhari, 2008). Those distinct yet complementary pieces of information can be integrated using bioinformatics (Abul-Husn et al, 2009; Reker and Malmström, 2012), computation, and mathematical modeling to bring a systems approach to alcohol research.

However, the application of such integrative methods is complicated by several intrinsic limitations that still need to be solved. First, computational models of systems-wide properties should be mainly used to make predictions and provide rationale for experimentation, and not to draw definitive conclusions. Second, it could be nearly impossible to accurately model certain gene-environment interactions that occur in living cells and organs. Indeed, addiction research is being continuously reshaped by increasingly sophisticated genetic tools. Nevertheless, we may not be able to decode the genetics of dependence until we reach a better understanding of how genes interact with environmental variables to influence alcohol responses and their related behaviors (Gorini et al, 2011; Mayfield et al, 2008). In addition, the bioinformatics field is advancing rapidly and is typically conducted by relatively specialized subgroups of researchers. Continuous advances in the field and low standardization require constant devotion and adaptation to newly developed software and tools; general accessibility remains limited because not all bench-based biologists can become computer programmers. In silico analyses are reshaping the idea of ownership of data, and multidisciplinary teamwork is often necessary to overcome technological difficulties.

In addition to the use of proteomic technologies, several researchers have already applied integrative approaches to the study of alcoholism by combining data obtained with different techniques. Briefly, Park and co-workers (2004) integrated their proteomic analysis of brains from B6 vs D2 mice with information on PPIs taken from web-based databases and built a linkage map to reveal the interrelationship of the alcohol-responsive proteins between different species (Park et al, 2004). In another study, an attempt to determine anxiety factors contributing to alcoholism was made by testing a transgenic mouse model for anxiety using three combined approaches: QTL analysis, microarray analysis, and shotgun proteomics of synaptosomes (Sikela et al, 2006). In their analysis of the DAT proteome, Maiya and co-workers (2007) identified DAT's PPIs, and also evaluated the biological significance of these proteins as a group. This was accomplished by determining expression levels of the genes encoding these proteins using computerized searches of existing databases of gene expression. The analysis found that the correlation between the expression levels of the genes encoding the various interacting proteins was greater than would be predicted by chance alone, suggesting common regulatory mechanisms and excluding experimental artifacts. Another group collected large-scale data sets for alcohol dependence and ethanol response in five different organisms and integrated these data with PPI databases to identify candidate alcoholsensitive genes (Guo et al, 2010a).

QTL studies have shown that differences in alcoholassociated sensitivity is, in general, under genetic control. Complex or quantitative traits are influenced by multiple genomic regions, referred to as QTLs. To date, many studies mapping QTLs associated with human diseases and complex traits have uncovered new loci and provided unexpected insights into the biology of diseases. For alcohol-associated behaviors, rodents have been used extensively to study alcohol-related phenotypes and the behavioral genetics of alcohol's action (Crabbe et al, 2010). Crosses between inbred strains are useful and valuable tools for determining which chromosomal regions control these genetic differences in alcohol-associated sensitivity. However, these loci account for only a small fraction of the total genetic variation associated with alcohol-induced effects and do not map to individual genes. Indeed, QTL regions are often very broad and contain many genes. Therefore, protein data provide additional information in search for the differentially expressed genes that explain phenotypic differences between strains. An innovative integrative proteomic approach has been used to search for quantitative trait genes (Fei et al, 2011). In this study, striatal synaptosomes from two mouse strains (alcohol-preferring B6 vs alcohol-avoiding D2) were compared, and differentially expressed proteins with coding regions within QTL regions were considered as 'quantitative trait proteins'. Differentially expressed protein groups were mapped to the 
genome, and $83 \%$ of them had members with coding sequences that fell within QTLs previously found between these strains, particularly within the replicable alcohol preference QTLs. This study demonstrated the utility of combining a proteomic data set with genetic and transcriptomic data between two strains of mice.

An integrative approach was used to combine data from miRNA and proteomic profiling in cerebral cortices and midbrains from C57BL/6J mice subjected to a CIE-2BC paradigm (Gorini et al, 2013b). A systems approach to data analysis combined miRNA and protein differential expression, miRNA and protein coexpression networks, miRNA target predictions, PPIs, and gene annotations to unveil crucial neurobiological alterations associated with alcohol dependence. The analysis identified modules of coexpressed miRNAs with a high correlation for CIE drinking phenotypes. In addition, some of these coexpressed miRNAs were predicted to target genes encoding differentially expressed proteins. Furthermore, certain proteins were in turn negatively correlated with these miRNA modules. Overall, the results of this comprehensive study provide an interpretation of differential expression data of individual miRNAs and proteins in terms of the relative contribution to alcohol dependence, and represent a model of how alcohol research can benefit from the application of system biology approaches to integrate complementary techniques.

Integrative approaches offer the best potential for advancing our knowledge of the complex mechanisms by which alcohol affects the brain and other organs. Continually evolving methodologies are essential for understanding the pathogenesis of alcohol dependence and for identifying therapeutic targets for treatment and prevention of the deleterious effects of this addictive substance.

\section{BIOMARKERS OF ALCOHOLISM}

The successful treatment of most diseases relies heavily upon early detection. Biomarkers with diagnostic and prognostic value are critical to the alcohol field. Most individuals with alcohol dependence or alcohol use problems evade detection until severe medical, legal, or social consequences arise. An obvious method to reveal acute alcohol consumption is to measure alcohol concentration in body fluids or breath, and small inexpensive instruments are routinely used for these purposes by law enforcement, medical, and security personnel. However, a reliable retrospective examination of alcohol intake across days or weeks remains more challenging. Indeed, the short half-life of alcohol in the blood after cessation of drinking eliminates the feasibility for using blood alcohol as a biomarker. Nevertheless, modern noninvasive wearable biosensors are capable to continuously measure transdermal alcohol vapor electrochemically, estimating when drinking has occurred and recording the drinking schedule (Sakai et al, 2006; Swift, 2003). In addition, biomarkers of alcohol intake with longer ranges of assessment have been identified. These biomarkers measure alcohol consumption indirectly, by detecting tissue damage or other physiological reactions to heavy drinking over time. For example, liver tests are available but may not identify abuse problems until advanced stages of the disease are present. This is further complicated by the fact that liver damage is not present in all alcoholics. For example, it has been reported that two-thirds of individuals with alcohol problems had normal liver function upon admission for treatment (Sobell et al, 1999). Development of a reliable molecular blood test for alcohol dependence and heavy drinking would be a milestone in the diagnosis and ultimate treatment of the disease (Freeman et al, 2010; Mayfield and Harris, 2009).

Carbohydrate-deficient transferrin (CDT) is one of the most specific serum marker of chronic, heavy alcohol use (Kasinathan et al, 2004; Reynaud et al, 2000). CDT has proven to be a useful diagnostic aid for suspected alcohol abuse and has received Food and Drug Administration approval. However, the low sensitivity of the CDT test in the general population makes it an unreliable candidate for predicting either heavy alcohol use or for diagnosing alcohol abuse and/or dependence (Aertgeerts et al, 2001; Alte et al, 2004; Neumann and Spies, 2003). Sensitivity of the CDT test varies from $\sim 20$ to $85 \%$ depending on the population being studied (Koch et al, 2004). The highest sensitivity rates were found in patients recruited from alcohol treatment programs, whereas some of the lowest sensitivities were observed in subjects in general medical settings. Thus, the accuracy or predictive value of the CDT test varies depending on the prevalence of heavy alcohol use in the population studied and is marginal in populations with a low prevalence of heavy alcohol use (Koch et al, 2004; Lijmer et al, 1999; Neumann and Spies, 2003). Other factors such as age and gender have also been shown to reduce CDT sensitivity (Conigrave et al, 2002; Montalto and Bean, 2003). Specificity also varies by population, and though initial studies suggested that CDT tests were highly specific, subsequent studies indicate a more complex picture as several biological factors have been shown to increase CDT levels. Moreover, the test in its current form is rather cumbersome, time consuming, and expensive (Javors and Johnson, 2003; Rosalki, 2004). Another serum marker that has been tested frequently is $\gamma$-glutamyltransferase (GGT). GGT is much less specific than CDT because GGT is also increased in non-alcohol-related liver diseases. The overall sensitivity of GGT and CDT are similar, and greater sensitivity has been reported by the combined measurement of GGT and CDT (Montalto and Bean, 2003). A third marker that has been tested is erythrocyte mean corpuscular volume, but this marker has a variable sensitivity and is nonspecific (Hock et al, 2005; Neumann and Spies, 2003; Schwan et al, 2004). Recently developed biomarkers include serotonin metabolites (Beck et al, 2007) and alcohol metabolites (Litten et al, 2010). Interestingly, ethyl glucuronide (EtG) (Borucki et al, 2007; Hoiseth et al, 2007; Kissack et $a l, 2008)$ can be detected in scalp or non-head hair up to 
several months after drinking has stopped (Bendroth et al, 2008; Litten et al, 2010; Pianta et al, 2013). Such properties designate EtG as promising alcohol metabolite biomarker, with potential use for forensic purposes, for the monitoring of abstinence among individuals convicted of driving while intoxicated (Wurst et al, 2008b) and women who are at risk for drinking during pregnancy (Pragst and Yegles, 2008; Wurst et al, 2008a).

To date, no clinical test is reliable enough on its own to support a diagnosis of active alcohol dependence or abuse in the general population. Indeed, traditional blood biomarker tests for detecting alcohol use have not been universally accepted or generally adopted in clinical practice because of their low accuracy, sensitivity, and specificity (Freeman and Vrana, 2010; Litten et al, 2010), as they are influenced by several factors including age, gender, and also on the population being studied (Mayfield and Harris, 2009). Combining two or more tests has been shown to improve predictive values for determining recent heavy use (Anton and Moak, 1994; Anton et al, 2002), indicating that monitoring more than a single marker may be critical as has been reported for cancer (Rhodes et al, 2004).

Biomarker development strategies involve the identification of proteins that differ in abundance between alcoholics and non-alcoholics and which can be easily measured to assess whether a person has been drinking alcohol recently or is an alcoholic. High-throughput technologies such as proteomics and genomics increase the possibility of discovering biomarker panels or signatures with the potential to be more sensitive and specific (Bearer et al, 2010; Torrente et al, 2012). Studies involving non-human primates might be promising as they do not present some of the limitations associated with the human subjects, such as inconsistent self-reporting of alcohol intake, variations in diet, and other individual differences between subjects. As basic scientists discover alcohol consumption biomarker signatures that reflect either alcohol intake or alcoholinduced organ damage, clinicians will ultimately provide the tools to translate the findings to patient populations and provide insight into how these markers may be included in routine alcohol abuse testing.

Future goals of alcohol biomarker research include the development of reliable blood tests for diagnosing alcoholism in the general population. The development of such tests would have important implications and would benefit the society, with increased detection, treatment, and prevention programs. Furthermore, unbiased detection of variable amounts of alcohol consumption can affect employment and forensic areas (Anton, 2010). A test for recent heavy drinking could be implemented in future drug screenings before/during employment or for obtaining licenses, especially for airline pilots, taxi, truck, and school bus drivers. Notably, the availability of a blood assay will lead to a faster and wider spread detection of alcoholism, with subsequent prompt treatment to disrupt the progression of the disease.

\section{CLINICAL IMPLICATIONS}

In the past century, alcoholism was mainly perceived as a moral failing and usually treated with long-term nonmedical therapies involving correction of related behaviors, cognitive behavioral therapy, psychological counseling, and mutual support groups (ie, Alcoholics Anonymous) (Leggio and Addolorato, 2010). Fortunately, current thoughts and attitudes about alcohol-use disorders are considerably different. Despite some rooted reticence in considering alcoholism strictly as a medical problem, alcohol and other addictive substance disorders are now more widely recognized as brain diseases, similar to other clinical psychiatric disorders (Addolorato et al, 2012). There is an increased awareness about genetic predisposition to alcoholism and long-lasting changes in neurotransmission systems associated with different phases of addiction. Consequently, treatment has progressed from social and behavioral therapies to complementary pharmacotherapies attempting to disrupt the mechanisms underlying this condition (Jupp and Lawrence, 2010). In the near future, the pharmacological treatment of alcohol-related disorders will gradually be integrated into the general health-care system. Ideal therapeutic approaches should combine both pharmacological and psychosocial treatments (Swift, 2007), given that the etiology of alcoholism includes genetic, neurobiological, psychological, and environmental factors (Koob, 2006). However, as diagnosis of alcoholism can be biased and problematic (Leggio and Addolorato, 2010), treatment trials are increasingly adopting biomarkers to help in the evaluation of standard interventions and new medications (Anton, 2010; Torrente et al, 2012). Biomarkers have the potential to serve as trait markers of alcoholrelated phenotypes, whose identification and categorization will characterize models for the multiple subtypes of alcohol dependence (Mayfield and Harris, 2009). Clinicians will then be better able to identify patients who are likely to respond positively or negatively to specific drugs and treatments. Therefore, biomarkers are expected to have a key role in future personalized protocols for the treatment of alcohol abuse (Litten et al, 2010).

\section{FUTURE RESEARCH DIRECTIONS}

As the initial results of the ENCODE project have been released, it is becoming clear that large portions of noncoding DNA are involved in regulating the expression of coding genes, and that gene regulation is far more complex than previously imagined (Dunham et al, 2012; Pennisi, 2012). Rapidly maturing DNA- and RNA-sequencing technologies are currently more comprehensive in covering whole genomes than proteome profiling. Nevertheless, the proteome exhibits unique complexity and dynamicity, and next-generation sequencing approaches still lack the ability to fully decode some key layers of gene expression regulation and network biology, such as PTMs. Therefore, proteomic analyses are gaining an indispensable complementary role 
in the study of complex diseases, and the list of techniques for studying proteomes is growing. Increasing evidence of limited correspondence between protein and mRNA levels requires protein, miRNA, and mRNA profiling to be applied in parallel, along with supportive biochemical and analytical techniques to fully understand gene regulation mechanisms underlying the neuronal adaptations related to dependence. Thus, development of novel proteomic strategies should be focused on complementing current transcriptomic techniques. Unbiased MS-based methods are rapidly becoming faster and more comprehensive (Altelaar et al, 2013), and are expected to be further improved to generate more sensitive and reproducible data. A better characterization of PTMs will be achieved through the development of more sensitive, refined, and improved methodologies and analytical tools. Indeed, modification-specific proteomics, which enables selective enrichment, purification, separation, and identification of various PTMs, will allow increasingly detailed analysis and quantitation of PTMs within proteins (Chung et al, 2013; Engholm-Keller and Larsen, 2013; Jensen, 2000; Zhao and Brasier, 2013) and will help elucidate their role in complex biological diseases like alcoholism. A reduction in the quantity of material required and analysis time necessary to obtain relevant proteomics data, while maintaining rigorous quality control, is also desirable.

With a significant shift in proteomics' throughput and pricing, in the next five years we expect a surge in publications where these methods will be applied to the study of neurobiology of addiction. Although previous studies have mostly reported changes engendered by alcohol consumption and exposure, low-cost access to an improved proteomics will lead to detailed studies where proteomes from discrete brain subregions will be profiled with an increased sample number and during different time points after withdrawal. Indeed, recent evidences in rodent models have suggested that, at least for cocaine or nicotine, a longer withdrawal corresponds to a greater drug-seeking, which may imply greater potential for relapse vulnerability (Gipson et al, 2013; Ben-Shahar et al, 2013). Long-lasting changes in the proteome that persist after protracted withdrawal and likely relate to relapse liability would be of high interest to translational scientist.

Many proteomic studies reviewed above provide lists of proteins with limited practical value. In the next few years, the required better avoidance of false positives will be reached with a combination of appropriate statistical filtering, extensive downstream functional analyses, experimental and computational validations with luciferase assays, immunoblotting, RT-qPCRs, and viral-mediated translational activation or suppression. This will restrict the number of candidate druggable targets and will hopefully lead to improved therapies for alcoholism.

Furthermore, the use of quantitative proteomic approaches to characterize targets of miRNAs has provided new tools for the study of miRNA biology. A number of miRNA targets important for other diseases are being discovered, allowing for functional analyses of miRNAmediated gene regulation and potentially leading to the development of novel therapeutic approaches. Thus, an increase in proteomic analyses aimed to understand the role of non-coding RNAs is expected in the near future (Grosshans and Filipowicz, 2008; Huang et al, 2013; Li et al, 2012), along with next-generation-based proteomics to enable an in-depth, multifaceted view of the proteome.

Some of the reviewed studies offer glimpses of innovative integrative methods that may become popular in the next years. The application of emerging systems biology approaches to the neurobiology of alcohol addiction can be technologically challenging. Nevertheless, significant progress has already been made and the impact of comprehensive systems biology in the study of alcoholrelated disorders promises to be ground-breaking. Innovative efforts to combine proteomics with other complementary postgenome platforms and integrate resulting information will accelerate its application in clinical practice and maximize its capabilities. These approaches are founded on the concept that alcohol-perturbed protein and gene regulatory networks differ from their normal counterparts (Hood et al, 2004; Weston and Hood, 2004). A better understanding of protein and gene regulatory networks underlying the neurobiology of alcohol addiction will pave the road for novel drug development strategies. Indeed, these networks share key nodal points that could represent more effective targets for therapeutic interventions. Systems approaches require the availability of reliable large and disparate data types from diverse technological platforms. Therefore, investigators need interdisciplinary skills to expand their research to new technological levels to include, for example, epigenomic, metabolomic, glycomic, modificomic, and other complementary proteomic approaches (Guo and Zakhari, 2008). Bioinformatics, computation, statistical analysis, and mathematical modeling are all crucial to integrate complex data sets generated through these techniques and to extract their global biological or clinical significance. Academic researchers would need better access to high-throughput facilities for DNA arrays, sequencing, genotyping, and various proteomic platforms. Development of more accessible databases and analysis software is also expected to allow more researchers to use integrative approaches. Advancing technological innovations will require standardization as well as collaborative crosstalk and multidisciplinary teamwork between different scientific communities.

Ultimately, we will decipher the molecular mechanisms underlying alcohol-use disorders and provide the foundation for their future prognosis, diagnosis, and treatment. In the case of alcoholism, investigators should find ways to prioritize the use of systems approaches. The boundaries between basic research and clinical applications of proteomics and systems biology are fading (Weston and Hood, 2004). These approaches will have a major role in creating a predictive, preventive, and personalized approach to medicine for addiction disorders. Proteomics is still a 
relatively immature technology and will require intensive efforts in the development of future strategies. Increasingly sophisticated proteomic methods are currently being developed in search of novel therapeutic targets and for better multiparameter diagnostics on alcohol-perturbed proteins and/or metabolites.

Snapshots of individual proteomes will likely be part of the development of personalized medicine of the future (Chen et al, 2012a). Over the next decades, when diagnostic tools will be more predictive and therapies more preventive, new cost-efficient and integrated technologies will allow individuals to have relevant portions of their genomes and proteomes sequenced; routine procedures for assessing health, disease status, and future disease risks will be available for each individual and will likely include multiparameter informative molecular diagnostics via blood analysis (Bailey, 2009; Hood et al, 2004; Mayfield and Harris, 2009). Improved proteomics, together with new technologies, will ultimately contribute to the design of preventive drugs for individuals with a genetic or psychosocial predisposition for alcoholism and offer a breakthrough in addiction treatment.

\section{FUNDING AND DISCLOSURE}

The authors declare no conflict of interest

\section{ACKNOWLEDGEMENTS}

We thank Dr Jody Mayfield for comments on the manuscript. GG, RAH, and RDM's research is supported by NIH Grants AA019382, AA0107838, AA020926, and AA016648.

\section{REFERENCES}

Abul-Husn NS, Bushlin I, Morón JA, Jenkins SL, Dolios G, Wang R et al. (2009). Systems approach to explore components and interactions in the presynapse. Proteomics 9: 3303-3315

Abul-Husn NS, Devi LA (2006). Neuroproteomics of the synapse and drug addiction. J Pharmacol Exp Ther 318: 461-468.

Addolorato G, Leggio L, Hopf FW, Diana M, Bonci A (2012). Novel therapeutic strategies for alcohol and drug addiction: focus on GABA, ion channels and transcranial magnetic stimulation. Neuropsychopharmacology 37: 163-177.

Aderem A (2005). Systems biology: its practice and challenges. Cell 121: 511-513.

Aertgeerts B, Buntinx F, Ansoms S, Fevery J (2001). Screening properties of questionnaires and laboratory tests for the detection of alcohol abuse or dependence in a general practice population. Br J Gen Pract 51: 206-217.

Alexander-Kaufman K, Cordwell S, Harper C, Matsumoto I (2007a). A proteome analysis of the dorsolateral prefrontal cortex in human alcoholic patients. Proteomics Clin Appl 1: 62-72.

Alexander-Kaufman K, Harper C, Wilce P, Matsumoto I (2007b). Cerebellar vermis proteome of chronic alcoholic individuals. Alcohol Clin Exp Res 31: 1286-1296.

Alexander-Kaufman K, James G, Sheedy D, Harper C, Matsumoto I (2006). Differential protein expression in the prefrontal white matter of human alcoholics: a proteomics study. Mol Psychiatry 11: 56-65.

Alte D, Luedemann J, Rose HJ, John U (2004). Laboratory markers carbohydratedeficient transferrin, gamma-glutamyltransferase, and mean corpuscular volume are not useful as screening tools for high-risk drinking in the general population: results from the Study of Health in Pomerania (SHIP). Alcohol Clin Exp Res 28: 931-940.

Altelaar AFM, Munoz J, Heck AJR (2013). Next-generation proteomics: towards an integrative view of proteome dynamics. Nat Rev Genet 14: 35-48. Describes the emerging next generation of proteomics and highlights its recent applications.
Anni H, Israel Y (2002). Proteomics in alcohol research. Alcohol Res Health 26: 219-232.

Anton RF (2010). Editorial commentary: alcohol biomarker papers. Alcohol Clin Exp Res 34: 939-940.

Anton RF, Lieber C, Tabakoff B (2002). Carbohydrate-deficient transferrin and gamma-glutamyltransferase for the detection and monitoring of alcohol use: results from a multisite study. Alcohol Clin Exp Res 26: 1215-1222.

Anton RF, Moak DH (1994). Carbohydrate-deficient transferrin and gammaglutamyltransferase as markers of heavy alcohol consumption: gender differences. Alcohol Clin Exp Res 18: 747-754.

Anton RF, O'Malley SS, Ciraulo DA, Cisler RA, Couper D, Donovan DM et al. (2006). Combined pharmacotherapies and behavioral interventions for alcohol dependence: the COMBINE study: a randomized controlled trial. JAMA 295: 2003-2017.

Arkin MR, Wells JA (2004). Small-molecule inhibitors of protein-protein interactions: progressing towards the dream. Nat Rev Drug Discov 3: 301-317.

Auffray C, Imbeaud S, Roux-Rouquié M, Hood L (2003). From functional genomics to systems biology: concepts and practices. C R Biol 326: 879-892.

Baek D, Villén J, Shin C, Camargo FD, Gygi SP, Bartel DP (2008). The impact of microRNAs on protein output. Nature 455: 64-71. Investigates the global effect of microRNAs on protein abundance using a stable-isotope labeling by amino acids in cell culture (SILAC)-based quantitative proteomics approach.

Bailey RC (2009). New multiparameter bioanalytical technologies for applications in personalized medicine, drug discovery, and fundamental biology. Bioanalysis 1: 1043-1047.

Bantscheff M, Schirle M, Sweetman G, Rick J, Kuster B (2007). Quantitative mass spectrometry in proteomics: a critical review. Anal Bioanal Chem 389: 1017-1031.

Barth J, Volknandt W (2011). Proteomic investigations of the synaptic vesicle interactome. Expert Rev Proteomics 8: 211-220.

Bearer CF, Bailey SM, Hoek JB (2010). Advancing alcohol biomarkers research. Alcohol Clin Exp Res 34: 941-945.

Beck O, Stephanson N, Bottcher M, Dahmen N, Fehr C, Helander A (2007). Biomarkers to disclose recent intake of alcohol: potential of 5-hydroxytryptophol glucuronide testing using new direct UPLC-tandem MS and ELISA methods. Alcohol Alcohol 42: 321-325.

Bell RL, Kimpel MW, Rodd ZA, Strother WN, Bai F, Peper CL et al. (2006). Protein expression changes in the nucleus accumbens and amygdala of inbred alcoholpreferring rats given either continuous or scheduled access to ethanol. Alcohol 40: 3-17.

Bell RL, Sable HJK, Colombo G, Hyytia P, Rodd ZA, Lumeng L (2012). Animal models for medications development targeting alcohol abuse using selectively bred rat lines: neurobiological and pharmacological validity. Pharmacol Biochem Behav 103: 119-155.

Bendroth P, Kronstrand R, Helander A, Greby J, Stephanson N, Krantz P (2008). Comparison of ethyl glucuronide in hair with phosphatidylethanol in whole blood as post-mortem markers of alcohol abuse. Forensic Sci Int 176: 76-81.

Benjamini Y, Hochberg Y (1995). Controlling the false discovery rate: a practical and powerful approach to multiple testing. J R Stat Socy Ser B 57: 289-300.

Ben-Shahar O, Sacramento AD, Miller BW, Webb SM, Wroten MG, Silva HE et al. (2013). Deficits in ventromedial prefrontal cortex group 1 metabotropic glutamate receptor function mediate resistance to extinction during protracted withdrawal from an extensive history of cocaine self-administration. J Neurosci 33: 495-506a.

Bhardwaj N, Lu H (2005). Correlation between gene expression profiles and protein-protein interactions within and across genomes. Bioinformatics 21: 2730-2738. Investigates the global relationship of protein-protein interactions with gene coexpression profiles for individual species and across evolutionary distant species.

Bhattacharyya SN, Habermacher R, Martine U, Closs El, Filipowicz W (2006). Relief of microRNA-mediated translational repression in human cells subjected to stress. Cell 125: 1111-1124.

Bhave SV, Hornbaker C, Phang TL, Saba L, Lapadat R, Kechris K et al. (2007). The PhenoGen informatics website: tools for analyses of complex traits. BMC Genet 8: 59.

Bierczynska-Krzysik A, Bonar E, Drabik A, Noga M, Suder P, Dylag T et al. (2006). Rat brain proteome in morphine dependence. Neurochem Int 49: 401-406.

Blednov YA, Borghese CM, McCracken ML, Benavidez JM, Geil CR, OsterndorffKahanek E et al. (2011). Loss of ethanol conditioned taste aversion and motor stimulation in knockin mice with ethanol-insensitive $\alpha 2$-containing GABA(A) receptors. J Pharmacol Exp Ther 336: 145-154.

Borghese CM, Harris RA (2012). Alcohol dependence and genes encoding $\alpha 2$ and $\gamma 1$ GABAA receptor subunits: insights from humans and mice. Alcohol Res 34: 345-353.

Borghese CM, Henderson LA, Bleck V, Trudell JR, Harris RA (2003). Sites of excitatory and inhibitory actions of alcohols on neuronal alpha2beta4 nicotinic acetylcholine receptors. J Pharmacol Exp Ther 307: 42-52. 
Borucki K, Dierkes J, Wartberg J, Westphal S, Genz A, Luley C (2007). In heavy drinkers, fatty acid ethyl esters remain elevated for up to $99 \mathrm{~h}$. Alcohol Clin Exp Res 31: 423-427.

Boukli NM, Saiyed ZM, Ricaurte M, Rodriguez JW, Ríos Olivares E, Cubano LA et al. (2010). Implications of ER stress, the unfolded protein response, and pro- and anti-apoptotic protein fingerprints in human monocyte-derived dendritic cells treated with alcohol. Alcohol Clin Exp Res 34: 2081-2088.

Brodin L, Low P, Shupliakov O (2000). Sequential steps in clathrin-mediated synaptic vesicle endocytosis. Curr Opin Neurobiol 10: 312-320.

Bull JH, Ellison G, Patel A, Muir G, Walker M, Underwood M et al. (2001). Identification of potential diagnostic markers of prostate cancer and prostatic intraepithelial neoplasia using cDNA microarray. $\mathrm{Br} J$ Cancer 84: 1512-1519.

Chen G, Gharib TG, Huang C-C, Taylor JMG, Misek DE, Kardia SLR et al. (2002). Discordant protein and mRNA expression in lung adenocarcinomas. Mol Cell Proteomics 1: 304-313.

Chen R, Mias Gl, Li-Pook-Than J, Jiang L, Lam HYK, Chen R et al. (2012a). Personal omics profiling reveals dynamic molecular and medical phenotypes. Cell 148: 1293-1307.

Chen Z-W, Fuchs K, Sieghart W, Townsend RR, Evers AS (2012b). Deep amino acid sequencing of native brain GABAA receptors using high-resolution mass spectrometry. Mol Cell Proteomics 11: M111. 011445.

Cheng MH, Coalson RD, Cascio M (2008). Molecular dynamics simulations of ethanol binding to the transmembrane domain of the glycine receptor: implications for the channel potentiation mechanism. Proteins 71: 972-981.

Chung C, Emili A, Frey BJ (2013). Non-parametric Bayesian approach to posttranslational modification refinement of predictions from tandem mass spectrometry. Bioinformatics 29: 821-829.

Conigrave KM, Degenhardt LJ, Whitfield JB, Saunders JB, Helander A, Tabakoff B (2002). CDT, GGT, and AST as markers of alcohol use: the WHO/ISBRA collaborative project. Alcohol Clin Exp Res 26: 332-339.

Coombs KM (2011). Quantitative proteomics of complex mixtures. Expert Rev Proteomics 8: 659-677. Provides a comprehensive overview of quantitative proteomics and related applications.

Crabbe JC, Phillips TJ, Belknap JK (2010). The complexity of alcohol drinking: studies in rodent genetic models. Behav Genet 40: 737-750.

Damodaran S, Dlugos CA, Wood TD, Rabin RA (2006). Effects of chronic ethanol administration on brain protein levels: a proteomic investigation using 2-D DIGE system. Eur J Pharmacol 547: 75-82.

Davis MA, Hanash S (2006). High-throughput genomic technology in research and clinical management of breast cancer. Plasma-based proteomics in early detection and therapy. Breast Cancer Res 8: 217.

Dayon L, Hainard A, Licker V, Turck N, Kuhn K, Hochstrasser DF et al. (2008). Relative quantification of proteins in human cerebrospinal fluids by MS/MS using 6-plex isobaric tags. Anal Chem 80: 2921-2931.

Deken SL, Beckman ML, Boos L, Quick MW (2000). Transport rates of GABA transporters: regulation by the N-terminal domain and syntaxin 1A. Nat Neurosci 3: $998-1003$

Dev KK (2004). Making protein interactions druggable: targeting PDZ domains. Nat Rev Drug Discov 3: 1047-1056.

Dlugos CA, Rabin RA (2003). Ethanol effects on three strains of zebrafish: model system for genetic investigations. Pharmacol Biochem Behav 74: 471-480.

Dodd PR, Lewohl JM (1998). Cell death mediated by amino acid transmitter receptors in human alcoholic brain damage: conflicts in the evidence. Ann NY Acad Sci 844: 50-58.

Drabik A, Bierczynska-Krzysik A, Bodzon-Kulakowska A, Suder P, Kotlinska J, Silberring $J$ (2007). Proteomics in neurosciences. Mass Spectrom Rev 26: 432-450.

Dunham I, Kundaje A, Aldred SF, Collins PJ, Davis CA, Doyle F et al. (2012). An integrated encyclopedia of DNA elements in the human genome. Nature 489: 57-74.

Engholm-Keller K, Larsen MR (2013). Technologies and challenges in large-scale phosphoproteomics. Proteomics 13: 910-931.

Etheridge N, Lewohl JM, Mayfield RD, Harris RA, Dodd PR (2009). Synaptic proteome changes in the superior frontal gyrus and occipital cortex of the alcoholic brain. Proteomics Clin Appl 3: 730-742. An elegant proteomic analysis of human brain regions showing synaptic-specific changes induced by alcoholism.

Etheridge N, Mayfield RD, Harris RA, Dodd PR (2011). Identifying changes in the synaptic proteome of cirrhotic alcoholic superior frontal gyrus. Curr Neuropharmacol 9: 122-128.

Fei SS, Wilmarth PA, Hitzemann RJ, McWeeney SK, Belknap JK, David LL (2011). Protein database and quantitative analysis considerations when integrating genetics and proteomics to compare mouse strains. J Proteome Res 10: 29052912. Demonstrates the utility of combining proteomic data sets with genetic, transcriptomic, and behavioral data
Filipowicz W, Bhattacharyya SN, Sonenberg N (2008). Mechanisms of post-transcriptional regulation by microRNAs: are the answers in sight? Nat Rev Genet 9: 102-114.

Foroud T, Phillips TJ (2012). Assessing the genetic risk for alcohol use disorders. Alcohol Res 34: 266-272.

Freeman WM, Salzberg AC, Gonzales SW, Grant KA, Vrana KE (2010). Classification of alcohol abuse by plasma protein biomarkers. Biol Psychiatry 68: 219-222.

Freeman WM, Vrana KE (2010). Future prospects for biomarkers of alcohol consumption and alcohol-induced disorders. Alcohol Clin Exp Res 34: 946-954.

Garbutt JC (2009). The state of pharmacotherapy for the treatment of alcohol dependence. J Subst Abuse Treat 36: S15-S23.

Garner CC, Nash J, Huganir RL (2000). PDZ domains in synapse assembly and signalling. Trends Cell Biol 10: 274-280.

Geschwind DH (2003). DNA microarrays: translation of the genome from laboratory to clinic. Lancet Neurol 2: 275-282.

Gipson CD, Reissner KJ, Kupchik YM, Smith ACW, Stankeviciute N, HensleySimon ME et al. (2013). Reinstatement of nicotine seeking is mediated by glutamatergic plasticity. Proc Natl Acad Sci USA 110: 9124-9129.

Godefroy O, Rousseaux M (1997). Novel decision making in patients with prefrontal or posterior brain damage. Neurology 49: 695-701.

Gorini G, Bell RL, Mayfield RD (2011). Molecular targets of alcohol action: Translational research for pharmacotherapy development and screening. Progr Mol Biol Transl Sci 98: 293-347. Describes neurobiological systems associated with molecular targets of alcohol, summarizing evidences from clinically relevant animal and human genomic/proteomic studies.

Gorini G, Roberts AJ, Mayfield RD (2013a). Neurobiological signatures of alcohol dependence revealed by protein profiling. PLOS ONE 8: e82656.

Gorini G, Nunez YO, Mayfield RD (2013b). Integration of miRNA and protein profiling reveals coordinated neuroadaptations in the alcohol-dependent mouse brain. PLOS ONE 8: e82565. The first report of combined ex vivo microRNA and proteomic profiling on a global scale from mammalian brain.

Gorini G, Ponomareva O, Shores KS, Person MD, Harris RA, Mayfield RD (2010). Dynamin-1 co-associates with native mouse brain BKCa channels: proteomics analysis of synaptic protein complexes. FEBS Lett 584: 845-851.

Greenbaum D, Colangelo C, Williams K, Gerstein M (2003). Comparing protein abundance and mRNA expression levels on a genomic scale. Genome Biol 4: 117.

Griffin TJ, Gygi SP, Ideker T, Rist B, Eng J, Hood L et al. (2002). Complementary profiling of gene expression at the transcriptome and proteome levels in Saccharomyces cerevisiae. Mol Cell Proteomics 1: 323-333.

Grosshans H, Filipowicz W (2008). Proteomics joins the search for microRNA targets. Cell 134: 560-562.

Gunzerath L, Hewitt BG, Li T-K, Warren KR (2011). Alcohol research: past, present, and future. Ann N Y Acad Sci 1216: 1-23.

Guo A-Y, Sun J, Jia P, Zhao Z (2010a). Network analysis of EtOH-related candidate genes. Chem Biodivers 7: 1142-1152. By combining several genetic datasets, provides a list of alcohol-related candidate genes and describes the ERGR database, examining functional and network features.

Guo H, Ingolia NT, Weissman JS, Bartel DP (2010b). Mammalian microRNAs predominantly act to decrease target mRNA levels. Nature 466: 835-840.

Guo QM, Zakhari S (2008). Commentary: systems biology and its relevance to alcohol research. Alcohol Res Health 31: 5-11. Describes systems approaches and their application to alcohol-induced disorders, with opportunities and challenges.

Gygi SP, Rochon Y, Franza BR, Aebersold R (1999). Correlation between protein and mRNA abundance in yeast. Mol Cell Biol 19: 1720-1730. A pioneering study delineating technical boundaries of quantitative proteomic approaches and revealing the limits of simple deduction of protein expression levels from mRNA transcript analysis.

Han S, Gelernter J, Kranzler HR, Yang B-Z (2012). Ordered subset linkage analysis based on admixture proportion identifies new linkage evidence for alcohol dependence in African-Americans. Hum Genet 132: 397-403.

Hargreaves GA, Quinn H, Kashem MA, Matsumoto I, McGregor IS (2009). Proteomic analysis demonstrates adolescent vulnerability to lasting hippocampal changes following chronic alcohol consumption. Alcohol Clin Exp Res 33: 86-94.

Harper C (2009). The neuropathology of alcohol-related brain damage. Alcohol Alcohol 44: 136-140.

Harris RA, Trudell JR, Mihic SJ (2008). Ethanol's molecular targets. Sci Signal 1: re7. Highlights a number of proteins for which considerable molecular level evidence for distinct ethanol binding sites has been described.

Hartwell LH, Hopfield JJ, Leibler S, Murray AW (1999). From molecular to modular cell biology. Nature 402: C47-C52.

Heilig M, Egli M (2006). Pharmacological treatment of alcohol dependence: target symptoms and target mechanisms. Pharmacol Ther 111: 855-876.

Hemby SE (2010). Cocainomics: new insights into the molecular basis of cocaine addiction. J Neuroimmune Pharmacol 5: 70-82. 
Hemby SE, Tannu N (2009). Modeling substance abuse for applications in proteomics. Methods Mol Biol 566: 69-83.

Hendrickson DG, Hogan DJ, McCullough HL, Myers JW, Herschlag D, Ferrell JE et al. (2009). Concordant regulation of translation and mRNA abundance for hundreds of targets of a human microRNA. PLOS Biol 7: e1000238.

Higgs RE, Knierman MD, Gelfanova V, Butler JP, Hale JE (2005). Comprehensive label-free method for the relative quantification of proteins from biological samples. J Proteome Res 4: 1442-1450.

Hock B, Schwarz M, Domke I, Grunert VP, Wuertemberger M, Schiemann U et al. (2005). Validity of carbohydrate-deficient transferrin (\%CDT), $\gamma$-glutamyltransferase $(\gamma-\mathrm{GT})$ and mean corpuscular erythrocyte volume (MCV) as biomarkers for chronic alcohol abuse: a study in patients with alcohol dependence and liver disorders of non-alcoholic and alcoholic origin. Addiction 100: 1477-1486.

Hoiseth G, Bernard JP, Karinen R, Johnsen L, Helander A, Christophersen AS et al. (2007). A pharmacokinetic study of ethyl glucuronide in blood and urine: applications to forensic toxicology. Forensic Sci Int 172: 119-124.

Hong-Brown LQ, Brown CR, Kazi AA, Huber DS, Pruznak AM, Lang CH (2010). Alcohol and PRAS40 knockdown decrease mTOR activity and protein synthesis via AMPK signaling and changes in mTORC1 interaction. J Cell Biochem 109: 1172-1184.

Hood L, Heath JR, Phelps ME, Lin B (2004). Systems biology and new technologies enable predictive and preventative medicine. Science 306: 640-643.

Howard RJ, Murail S, Ondricek KE, Corringer P-J, Lindahl E, Trudell JR et al. (2011). Structural basis for alcohol modulation of a pentameric ligand-gated ion channel. Proc Natl Acad Sci USA 108: 12149-12154.

Huang T-C, Pinto SM, Pandey A (2013). Proteomics for understanding miRNA biology. Proteomics 13: 558-567. A review focusing on the role of proteomics and novel labeling strategies to understand microRNA biology.

Husi H, Ward MA, Choudhary JS, Blackstock WP, Grant SG (2000). Proteomic analysis of NMDA receptor-adhesion protein signaling complexes. Nat Neurosci 3: 661-669.

Hyman SE, Malenka RC, Nestler EJ (2006). Neural mechanisms of addiction: the role of reward-related learning and memory. Annu Rev Neurosci 29: 565-598.

ttiwut C, Yang B-Z, Kranzler HR, Anton RF, Hirunsatit R, Weiss RD et al. (2012). GABRG1 and GABRA2 variation associated with alcohol dependence in African Americans. Alcohol Clin Exp Res 36: 588-593.

Javors MA, Johnson BA (2003). Current status of carbohydrate deficient transferrin, total serum sialic acid, sialic acid index of apolipoprotein $J$ and serum beta-hexosaminidase as markers for alcohol consumption. Addiction 98(Suppl 2): $45-50$.

Jensen ON (2000). Modification-specific proteomics: systematic strategies for analysing post-translationally modified proteins. Trends Biotechnol 18(Suppl 1): 36-42.

Jensen ON (2004). Modification-specific proteomics: characterization of posttranslational modifications by mass spectrometry. Curr Opin Chem Biol 8: 33-41.

Jupp B, Lawrence AJ (2010). New horizons for therapeutics in drug and alcohol abuse. Pharmacol Ther 125: 138-168.

Kashem MA, Ahmed S, Sarker R, Ahmed EU, Hargreaves GA, McGregor IS (2012). Long-term daily access to alcohol alters dopamine-related synthesis and signaling proteins in the rat striatum. Neurochem Int 61: 1280-1288.

Kashem MA, Etages HD, Kopitar-Jerala N, McGregor IS, Matsumoto I (2009). Differential protein expression in the corpus callosum (body) of human alcoholic brain. J Neurochem 110: 486-495.

Kashem MA, Harper C, Matsumoto I (2008). Differential protein expression in the corpus callosum (genu) of human alcoholics. Neurochem Int 53: 1-11.

Kashem MA, James G, Harper C, Wilce P, Matsumoto I (2007). Differential protein expression in the corpus callosum (splenium) of human alcoholics: a proteomics study. Neurochem Int 50: 450-459.

Kasinathan C, Vrana K, Beretta L, Thomas P, Gooch R, Worst T et al. (2004). The future of proteomics in the study of alcoholism. Alcohol Clin Exp Res 28: 228-232.

Kaur P, Chance MR (2012). The utility of mass spectrometry based structural proteomics in biopharmaceutical biologics development. Integr Proteomics 442. Available at: http://www.intechopen.com/books/integrative-proteomics/theutility-of-mass-spectrometry-based-structural-proteomics-in-biopharmaceutical-biologics-developm.

Kemming D, Vogt U, Tidow N, Schlotter CM, Bürger H, Helms MW et al. (2006). Whole genome expression analysis for biologic rational pathway modeling: application in cancer prognosis and therapy prediction. Mol Diagn Ther 10: 271-280.

Khanna R, Zougman A, Stanley EF (2007). A proteomic screen for presynaptic terminal N-type calcium channel (CaV2.2) binding partners. J Biochem Mol Biol 40: 302-314

Kim N, Han JY, Roh GS, Kim HJ, Kang SS, Cho GJ et al. (2012). Nuclear clusterin is associated with neuronal apoptosis in the developing rat brain upon ethanol exposure. Alcohol Clin Exp Res 36: 72-82.
Kim YJ, Doyle ML (2010). Structural mass spectrometry in protein therapeutics discovery. Anal Chem 82: 7083-7089.

Kirschner MW (2005). The meaning of systems biology. Cell 121: 503-504.

Kissack JC, Bishop J, Roper AL (2008). Ethylglucuronide as a biomarker for ethanol detection. Pharmacotherapy 28: 769-781.

Klemmer P, Smit AB, Li KW (2009). Proteomics analysis of immuno-precipitated synaptic protein complexes. J Proteomics 72: 82-90.

Koch H, Meerkerk GJ, Zaat JO, Ham MF, Scholten RJ, Assendelft WJ (2004). Accuracy of carbohydrate-deficient transferrin in the detection of excessive alcohol consumption: a systematic review. Alcohol Alcohol 39: 75-85.

Konkimalla VB, Suhas VL, Chandra NR, Gebhart E, Efferth T (2007). Diagnosis and therapy of oral squamous cell carcinoma. Expert Rev Anticancer Ther 7: 317-329.

Koob GF (2006). The neurobiology of addiction: a neuroadaptational view relevant for diagnosis. Addiction 101(Suppl 1): 23-30.

Koob GF, Le Moal M (2001). Drug addiction, dysregulation of reward, and allostasis. Neuropsychopharmacology 24: 97-129. Clear outline of the allostasis hypothesis of the transition of addiction from social to compulsive use patterns.

Kril JJ, Harper CG (1989). Neuronal counts from four cortical regions of alcoholic brains. Acta Neuropathol 79: 200-204.

Langfelder P, Horvath S (2008). WGCNA: an R package for weighted correlation network analysis. BMC Bioinform 9: 559.

Le MTN, Xie H, Zhou B, Chia PH, Rizk P, Um M et al. (2009). MicroRNA-125b promotes neuronal differentiation in human cells by repressing multiple targets. Mol Cell Biol 29: 5290-5305.

Lea P, Ling M (2008). New molecular assays for cancer diagnosis and targeted therapy. Curr Opin Mol Ther 10: 251-259.

Lee HT, Kim SK, Choi MR, Park JH, Jung KH, Chai YG (2013). Effects of the activated mitogen-activated protein kinase pathway via the c-ros receptor tyrosine kinase on the T47D breast cancer cell line following alcohol exposure. Oncol Rep 29: 868-874.

Leggio L, Addolorato G (2010). Pharmacotherapy of alcohol dependence: past, present and future research. Curr Pharm Des 16: 2074-2075.

Leite JF, Amoscato AA, Cascio M (2000). Coupled proteolytic and mass spectrometry studies indicate a novel topology for the glycine receptor. J Biol Chem 275: 13683-13689.

Leite JF, Cascio M (2001). Structure of ligand-gated ion channels: critical assessment of biochemical data supports novel topology. Mol Cell Neurosci 17: 777-792

Leung AKL, Young AG, Bhutkar A, Zheng GX, Bosson AD, Nielsen CB et al. (2011). Genome-wide identification of Ago2 binding sites from mouse embryonic stem cells with and without mature microRNAs. Nat Struct Mol Biol 18: 237-244.

Lewohl JM, Dyk DD, Van, Craft GE, Innes DJ, Mayfield RD, Cobon G et al. (2004). The application of proteomics to the human alcoholic brain. Ann N Y Acad Sci 1025: 14-26. Describes the first application of global proteomics to study human alcoholic brain

Lewohl JM, Nunez YO, Dodd PR, Tiwari GR, Harris RA, Mayfield RD (2011). Upregulation of microRNAs in brain of human alcoholics. Alcohol Clin Exp Res 35: 1928-1937. Provides the first microRNA microarray analysis of human alcoholic brain in context of related changes in gene expression.

Li C, Xiong Q, Zhang J, Ge F, Bi L-J (2012). Quantitative proteomic strategies for the identification of microRNA targets. Expert Rev Proteomics 9: 549-559.

Li KW, Klemmer P, Smit AB (2010). Interaction proteomics of synapse protein complexes. Anal Bioanal Chem 397: 3195-3202.

Li MD, Wang J (2007). Neuroproteomics and its applications in research on nicotine and other drugs of abuse. Proteomics Clin Appl 1: 1406-1427.

Lijmer JG, Mol BW, Heisterkamp S, Bonsel GJ, Prins MH, van der Meulen JH et al. (1999). Empirical evidence of design-related bias in studies of diagnostic tests. JAMA 282: 1061-1066.

Litten RZ, Bradley AM, Moss HB (2010). Alcohol biomarkers in applied settings: recent advances and future research opportunities. Alcohol Clin Exp Res 34: 955-967.

Liu ET (2005). Systems biology, integrative biology, predictive biology. Cell 121: 505-506.

Liu J, Lewohl JM, Harris RA, Dodd PR, Mayfield RD (2007). Altered gene expression profiles in the frontal cortex of cirrhotic alcoholics. Alcohol Clin Exp Res 31: 1460-1466.

Liu J, Lewohl JM, Harris RA, lyer VR, Dodd PR, Randall PK et al. (2006). Patterns of gene expression in the frontal cortex discriminate alcoholic from nonalcoholic individuals. Neuropsychopharmacology 31: 1574-1582.

Lopez MF, Becker HC (2005). Effect of pattern and number of chronic ethanol exposures on subsequent voluntary ethanol intake in C57BL/6J mice. Psychopharmacology 181: 688-696.

Lovinger DM (2006). Mixing proteomics and alcohol. Alcohol 40: 1-2. 
Lu J, Helton TD, Blanpied TA, Rácz B, Newpher TM, Weinberg RJ et al. (2007). Postsynaptic positioning of endocytic zones and AMPA receptor cycling by physical coupling of dynamin-3 to Homer. Neuron 55: 874-889.

Lu LJ, Xia Y, Paccanaro A, Yu H, Gerstein M (2005). Assessing the limits of genomic data integration for predicting protein networks. Genome Res 15: 945-953.

Lull ME, Freeman WM, VanGuilder HD, Vrana KE (2010). The use of neuroproteomics in drug abuse research. Drug Alcohol Depend 107: 11-22.

Maiya R, Ponomarev I, Linse KD, Harris RA, Mayfield RD (2007). Defining the dopamine transporter proteome by convergent biochemical and in silico analyses. Genes Brain Behav 6: 97-106.

Maldonado-Devincci AM, Stevens SM Jr, Kirstein CL (2012). Investigation of agespecific behavioral and proteomic changes in an animal model of chronic ethanol exposure. Methods Mol Biol 829: 471-485.

Mane SP, Evans C, Cooper KL, Crasta OR, Folkerts O, Hutchison SK et al. (2009). Transcriptome sequencing of the Microarray Quality Control (MAQC) RNA reference samples using next generation sequencing. BMC Genomics 10: 264.

Mann M (2009). Comparative analysis to guide quality improvements in proteomics. Nat Methods 6: 717-719.

Marcilla M, Albar JP (2013). Quantitative proteomics: a strategic ally to map protein interaction networks. IUBMB Life 65: 9-16.

Marcotte ER, Srivastava LK, Quirion R (2003). cDNA microarray and proteomic approaches in the study of brain diseases: focus on schizophrenia and Alzheimer's disease. Pharmacol Ther 100: 63-74.

Martin-Fardon R, Weiss F (2013). Modeling relapse in animals. Curr Top Behav Neurosci 13: 403-432.

Matsuda-Matsumoto H, Iwazaki T, Kashem MA, Harper C, Matsumoto I (2007). Differential protein expression profiles in the hippocampus of human alcoholics. Neurochem Int 51: 370-376.

Matsumoto I (2009). Proteomics approach in the study of the pathophysiology of alcohol-related brain damage. Alcohol Alcohol 44: 171-176. An authoritative overview of neuroproteomic studies from several human alcoholic brain regions with a focus on related tissue damage and cognitive dysfunctions.

Mayfield RD, Harris RA (2009). Gene expression profiling in blood: new diagnostics in alcoholism and addiction? Neuropsychopharmacology 34: 250-251.

Mayfield RD, Harris RA, Schuckit MA (2008). Genetic factors influencing alcohol dependence. Br J Pharmacol 154: 275-287.

McBride WJ, Schultz JA, Kimpel MW, McClintick JN, Wang M, You J et al. (2009). Differential effects of ethanol in the nucleus accumbens shell of alcohol-preferring (P), alcohol-non-preferring (NP) and Wistar rats: a proteomics study. Pharmacol Biochem Behav 92: 304-313.

McCracken LM, Blednov YA, Trudell JR, Benavidez JM, Betz H, Harris RA (2013). Mutation of a zinc-binding residue in the glycine receptor $\alpha 1$ subunit changes ethanol sensitivity in vitro and alcohol consumption in vivo. J Pharmacol Exp Ther 344: 489-500.

McCracken ML, Borghese CM, Trudell JR, Harris RA (2010). A transmembrane amino acid in the GABAA receptor $\beta 2$ subunit critical for the actions of alcohols and anesthetics. J Pharmacol Exp Ther 335: 600-606.

Miranda RC, Pietrzykowski AZ, Tang Y, Sathyan P, Mayfield D, Keshavarzian A et al. (2010). MicroRNAs: master regulators of ethanol abuse and toxicity? Alcohol Clin Exp Res 34: 575-587.

Mirnics K, Middleton FA, Marquez A, Lewis DA, Levitt P (2000). Molecular characterization of schizophrenia viewed by microarray analysis of gene expression in prefrontal cortex. Neuron 28: 53-67.

Montalto NJ, Bean P (2003). Use of contemporary biomarkers in the detection of chronic alcohol use. Med Sci Monit 9: RA285-RA290.

Moreira S, Breton S, Burger G (2012). Unscrambling genetic information at the RNA level. Wiley Interdiscip Rev RNA 3: 213-228.

Mortazavi A, Williams BA, McCue K, Schaeffer L, Wold B (2008). Mapping and quantifying mammalian transcriptomes by RNA-Seq. Nat Methods 5 : $621-628$.

Mulligan MK, Ponomarev I, Hitzemann RJ, Belknap JK, Tabakoff B, Harris RA et al. (2006). Toward understanding the genetics of alcohol drinking through transcriptome meta-analysis. Proc Natl Acad Sci USA 103: 6368-6373. A meta-analysis of several microarray datasets to study alcohol preference phenotypes.

Mulligan MK, Rhodes JS, Crabbe JC, Mayfield RD, Adron Harris R, Ponomarev I (2011). Molecular profiles of drinking alcohol to intoxication in C57BL/6J mice. Alcohol Clin Exp Res 35: 659-670.

Murail S, Howard RJ, Broemstrup T, Bertaccini EJ, Harris RA, Trudell JR et al. (2012). Molecular mechanism for the dual alcohol modulation of Cys-loop receptors. PLoS Comput Biol 8: e1002710.

Muth TR, Ahn J, Caplan MJ (1998). Identification of sorting determinants in the C-terminal cytoplasmic tails of the gamma-aminobutyric acid transporters GAT-2 and GAT-3. J Biol Chem 273: 25616-25627.
Nam HW, Lee MR, Zhu Y, Wu J, Hinton DJ, Choi S et al. (2011). Type 1 equilibrative nucleoside transporter regulates ethanol drinking through accumbal $N$-methyl-Daspartate receptor signaling. Biol Psychiatry 69: 1043-1051.

Nestler EJ (2000). Genes and addiction. Nat Genet 26: 277-281.

Nestler EJ (2005). Is there a common molecular pathway for addiction? Nat Neurosci 8: 1445-1449.

Neuhold LA, Guo QM, Alper J, Velazquez JM (2004). High-throughput proteomics for alcohol research. Alcohol Clin Exp Res 28: 203-210.

Neumann T, Spies C (2003). Use of biomarkers for alcohol use disorders in clinical practice. Addiction 98(Suppl 2): 81-91.

Nunez YO, Mayfield RD (2012). Understanding alcoholism through microRNA signatures in brains of human alcoholics. Frontiers in genetics 3: 43. Focuses on microRNA signatures in human alcoholic brain related to changes in gene expression and highlights putative neuronal adaptation mechanisms responsible for the development of alcoholism.

Nutt DJ, King LA, Phillips LD (2010). Drug harms in the UK: a multicriteria decision analysis. Lancet 376: 1558-1565.

Nuutinen T, Suuronen T, Kauppinen A, Salminen A (2009). Clusterin: a forgotten player in Alzheimer's disease. Brain Res Rev 61: 89-104.

Okutsu J, Tsunoda T, Kaneta Y, Katagiri T, Kitahara O, Zembutsu H et al. (2002). Prediction of chemosensitivity for patients with acute myeloid leukemia, according to expression levels of 28 genes selected by genome-wide complementary DNA microarray analysis. Mol Cancer Ther 1: 1035-1042.

Ong S-E, Blagoev B, Kratchmarova I, Kristensen DB, Steen H, Pandey A et al. (2002). Stable isotope labeling by amino acids in cell culture, SILAC, as a simple and accurate approach to expression proteomics. Mol Cell Proteomics 1: 376-386.

Padayatti PS, Wang L, Gupta S, Orban T, Sun W, Salom D et al. (2013). A hybrid structural approach to analyze ligand binding by the 5-HT4 receptor. Mol Cell Proteomics 12: 1259-1271.

Papagiannakopoulos T, Kosik KS (2009). MicroRNA-124: micromanager of neurogenesis. Cell Stem Cell 4: 375-376.

Park B, Jeong S-K, Lee W-S, Seong JK, Paik Y-K (2004). A simple pattern classification method for alcohol-responsive proteins that are differentially expressed in mouse brain. Proteomics 4: 3369-3375.

Patel VJ, Thalassinos K, Slade SE, Connolly JB, Crombie A, Murrell JC et al. (2009). A Comparison of Labeling and Label-Free Mass Spectrometry-Based Proteomics Approaches. J Proteome Res 8: 3752-3759.

Pennisi E (2012). Genomics. ENCODE project writes eulogy for junk DNA. Science 337: 1161.

Pfefferbaum A (2004). Alcoholism damages the brain, but does moderate alcohol use? Lancet Neurol 3: 143-144.

Phillips TJ, Belknap JK (2002). Complex-trait genetics: emergence of multivariate strategies. Nat Rev Neurosci 3: 478-485. A perspective on alcoholism focused on its nature of complex trait disorder, with details on strategies to study influences by multiple genes.

Pianta A, Liniger B, Baumgartner MR (2013). Ethyl glucuronide in scalp and non-head hair: an intra-individual comparison. Alcohol Alcohol 48: 295-302.

Pietrzykowski AZ, Friesen RM, Martin GE, Puig SI, Nowak CL, Wynne PM et al. (2008). Posttranscriptional regulation of BK channel splice variant stability by miR-9 underlies neuroadaptation to alcohol. Neuron 59: 274-287.

Pillai RS, Bhattacharyya SN, Artus CG, Zoller T, Cougot N, Basyuk E et al. (2005). Inhibition of translational initiation by Let-7 MicroRNA in human cells. Science 309: 1573-1576.

Pitel AL, Beaunieux H, Witkowski T, Vabret F, Guillery-Girard B, Quinette P et al. (2007). Genuine episodic memory deficits and executive dysfunctions in alcoholic subjects early in abstinence. Alcohol Clin Exp Res 31: 1169-1178.

Plazas-Mayorca MD, Vrana KE (2011). Proteomic investigation of epigenetics in neuropsychiatric disorders: a missing link between genetics and behavior? $J$ Proteome Res 10: 58-65.

Ponomarev I, Wang S, Zhang L, Harris RA, Mayfield RD (2012). Gene coexpression networks in human brain identify epigenetic modifications in alcohol dependence. J Neurosci 32: 1884-1897. The first application of a systems approach to transcriptome profiling of human alcoholic brain, with an integrated view of molecular and cellular changes underlying alcohol addiction and evidences on epigenetic modifications.

Potenza MN, Sofuoglu M, Carroll KM, Rounsaville BJ (2011). Neuroscience of behavioral and pharmacological treatments for addictions. Neuron 69: 695-712.

Pragst F, Yegles M (2008). Determination of fatty acid ethyl esters (FAEE) and ethyl glucuronide (EtG) in hair: a promising way for retrospective detection of alcohol abuse during pregnancy? Ther Drug Monit 30: 255-263.

Přikrylová Vranová H, Mareš J, Nevrlý M, Stejskal D, Zapletalová J, Hluštík P et al. (2010). CSF markers of neurodegeneration in Parkinson's disease. J Neural Transm 117: 1177-1181. 
Procopio DO, Saba LM, Walter H, Lesch O, Skala K, Schlaff G et al. (2012). Genetic markers of comorbid depression and alcoholism in women. Alcohol Clin Exp Res 37: 896-904.

Rahman S, Sahakian BJ, Hodges JR, Rogers RD, Robbins TW (1999). Specific cognitive deficits in mild frontal variant frontotemporal dementia. Brain 122(Part 8): $1469-1493$

Ramani AK, Bunescu RC, Mooney RJ, Marcotte EM (2005). Consolidating the set of known human protein-protein interactions in preparation for large-scale mapping of the human interactome. Genome Biol 6: R40.

Ratti MT, Bo P, Giardini A, Soragna D (2002). Chronic alcoholism and the frontal lobe: which executive functions are imparied? Acta Neurol Scand 105: 276-281.

Reilly MT, Cunningham KA, Natarajan A (2009). Protein-protein interactions as therapeutic targets in neuropsychopharmacology. Neuropsychopharmacology 34: 247-248.

Reilly MT, Harris RA, Noronha A (2012). Using genetically engineered animal models in the postgenomic era to understand gene function in alcoholism. Alcohol Res 34: 282-291.

Reker D, Malmström L (2012). Bioinformatic challenges in targeted proteomics. J Proteome Res 11: 4393-4402.

Renthal W, Nestler EJ (2009). Chromatin regulation in drug addiction and depression. Dialogues Clin Neurosci 11: 257-268.

Reynaud M, Schellenberg F, Loisequx-Meunier MN, Schwan R, Maradeix B, Planche F et al. (2000). Objective diagnosis of alcohol abuse: compared values of carbohydrate-deficient transferrin (CDT), gamma-glutamyl transferase (GGT), and mean corpuscular volume (MCV). Alcohol Clin Exp Res 24: 1414-1419.

Rhodes DR, Yu J, Shanker K, Deshpande N, Varambally R, Ghosh D et al. (2004). Large-scale meta-analysis of cancer microarray data identifies common transcriptional profiles of neoplastic transformation and progression. Proc Nat/ Acad Sci USA 101: 9309-9314.

Roberts JA, Bottrill AR, Mistry S, Evans RJ (2012). Mass spectrometry analysis of human $\mathrm{P} 2 \times 1$ receptors; insight into phosphorylation, modelling and conformational changes. J Neurochem 123: 725-735.

Rodd ZA, Bertsch BA, Strother WN, Le-Niculescu H, Balaraman Y, Hayden E et al. (2007). Candidate genes, pathways and mechanisms for alcoholism: an expanded convergent functional genomics approach. Pharmacogenom $J 7$ : 222-256.

Rogowska-Wrzesinska A, Bihan M-C, Le, Thaysen-Andersen M, Roepstorff P (2013). 2D gels still have a niche in proteomics. J Proteomics 88: 4-13.

Romanova EV, Lee JE, Kelleher NL, Sweedler JV, Gulley JM (2012). Comparative peptidomics analysis of neural adaptations in rats repeatedly exposed to amphetamine. J Neurochem 123: 276-287.

Rosalki SB (2004). Carbohydrate-deficient transferrin: a marker of alcohol abuse. Int J Clin Pract 58: 391-393.

Ross PL, Huang YN, Marchese JN, Williamson B, Parker K, Hattan S et al. (2004). Multiplexed protein quantitation in Saccharomyces cerevisiae using aminereactive isobaric tagging reagents. Mol Cell Proteomics 3: 1154-1169.

Saito M, Smiley J, Toth R, Vadasz C (2002). Microarray analysis of gene expression in rat hippocampus after chronic ethanol treatment. Neurochem Res 27: 1221-1229.

Sakai JT, Mikulich-Gilbertson SK, Long RJ, Crowley TJ (2006). Validity of transdermal alcohol monitoring: fixed and self-regulated dosing. Alcohol Clin Exp Res 30: 26-33.

Sari Y, Zhang M, Mechref Y (2010). Differential expression of proteins in fetal brains of alcohol-treated prenatally C57BL/6 mice: a proteomic investigation. Electrophoresis 31: 483-496

Sauguet L, Poitevin F, Murail S, Renterghem C, Van, Moraga-Cid G, Malherbe L et al. (2013). Structural basis for ion permeation mechanism in pentameric ligand-gated ion channels. EMBO J 32: 728-741.

Schuckit MA (2009). An overview of genetic influences in alcoholism. J Subst Abuse Treat 36: S5-14. A review that summarizes recent findings from human research regarding genetic influences in alcohol abuse and dependence.

Schwan R, Albuisson E, Malet L, Loiseaux M-N, Reynaud M, Schellenberg F et al. (2004). The use of biological laboratory markers in the diagnosis of alcohol misuse: an evidence-based approach. Drug Alcohol Depend 74: 273-279.

Schwanhäusser B, Busse D, Li N, Dittmar G, Schuchhardt J, Wolf J et al. (2011). Global quantification of mammalian gene expression control. Nature 473: 337-342. Presents a comprehensive quantitative analysis of transcription and translation rates, showing evidence that protein abundance is mainly regulated at the translation level.

Serpa JJ, Parker CE, Petrotchenko EV, Han J, Pan J, Borchers CH (2012). Mass spectrometry-based structural proteomics. Eur J Mass Spectrom (Chichester, UK) 18: 251-267.

Shen Q, Temple S (2009). Fine control: microRNA regulation of adult neurogenesis. Nat Neurosci 12: 369-370.
Sherwood CA, Eastham A, Lee LW, Risler J, Mirzaei H, Falkner JA et al. (2009). Rapid optimization of MRM-MS instrument parameters by subtle alteration of precursor and product $\mathrm{m} / \mathrm{z}$ targets. J Proteome Res 8: 3746-3751.

Shi T, Su D, Liu T, Tang K, Camp DG II, Qian W-J et al. (2012). Advancing the sensitivity of selected reaction monitoring-based targeted quantitative proteomics. Proteomics 12: 1074-1092.

Sikela JM, Maclaren EJ, Kim Y, Karimpour-Fard A, Cai W-W, Pollack J et al. (2006). DNA microarray and proteomic strategies for understanding alcohol action. Alcohol Clin Exp Res 30: 700-708.

Sircar R, Sircar D (2005). Adolescent rats exposed to repeated ethanol treatment show lingering behavioral impairments. Alcohol Clin Exp Res 29: 1402-1410.

Smith AD, Weiss F (1999). Ethanol exposure differentially alters central monoamine neurotransmission in alcohol-preferring versus -nonpreferring rats. J Pharmacol Exp Ther 288: 1223-1228.

Smith DI (2002). Transcriptional profiling develops molecular signatures for ovarian tumors. Cytometry 47: 60-62.

Sobell LC, Agrawal S, Sobell MB (1999). Utility of liver function tests for screening 'alcohol abusers' who are not severely dependent on alcohol. Subst Use Misuse 34: 1723-1732.

Song Z, Guo Q, Zhang J, Li M, Liu C, Zou W (2012). Proteomic analysis of PKC $\gamma$ related proteins in the spinal cord of morphine-tolerant rats. PLoS One 7: e42068.

Spanagel R (2005). How to measure relapse in animals. Drugs Rel Prev Alcohol 13-21. Available at: http://link.springer.com/chapter/10.1007/3-7643-7305-9_2.

Spanagel R (2009). Alcoholism: a systems approach from molecular physiology to addictive behavior. Physiol Rev 89: 649-705.

Staub O, Rotin D (1997). Regulation of ion transport by protein-protein interaction domains. Curr Opin Nephrol Hypertens 6: 447-454

Sullivan EV, Pfefferbaum A (2005). Neurocircuitry in alcoholism: a substrate of disruption and repair. Psychopharmacology (Berl) 180: 583-594.

Sung U, Jennings JL, Link AJ, Blakely RD (2005). Proteomic analysis of human norepinephrine transporter complexes reveals associations with protein phosphatase 2A anchoring subunit and 14-3-3 proteins. Biochem Biophys Res Commun 333: 671-678.

Swift R (2003). Direct measurement of alcohol and its metabolites. Addiction 98(Suppl 2): 73-80.

Swift R (2007). Emerging approaches to managing alcohol dependence. Am J Health Syst Pharm 64: S12-S22.

Tabakoff B, Saba L, Printz M, Flodman P, Hodgkinson C, Goldman D et al. (2009). Genetical genomic determinants of alcohol consumption in rats and humans. BMC Biol 7: 70.

Tang F, Barbacioru C, Wang Y, Nordman E, Lee C, Xu N et al. (2009). mRNA-Seq whole-transcriptome analysis of a single cell. Nat Methods 6: 377-382.

Tapocik JD, Solomon M, Flanigan M, Meinhardt M, Barbier E, Schank JR et al. (2013). Coordinated dysregulation of mRNAs and microRNAs in the rat medial prefrontal cortex following a history of alcohol dependence. Pharmacogenom J 13: 286-296. Integrates brain microRNA and gene expression profiling from a rat model of alcohol dependence.

Taxman DJ, MacKeigan JP, Clements C, Bergstralh DT, Ting JP (2003). Transcriptional profiling of targets for combination therapy of lung carcinoma with paclitaxel and mitogen-activated protein/extracellular signal-regulated kinase kinase inhibitor. Cancer Res 63: 5095-5104.

Tkachev D, Mimmack ML, Ryan MM, Wayland M, Freeman T, Jones PB et al. (2003). Oligodendrocyte dysfunction in schizophrenia and bipolar disorder. Lancet 362: 798-805.

Torrente MP, Freeman WM, Vrana KE (2012). Protein biomarkers of alcohol abuse. Expert Rev Proteomics 9: 425-436. Encapsulates recent advances in proteomic technologies with potential use in alcohol abuse biomarker discovery and summarizes established and novel protein biomarkers for long-term alcohol consumption.

Treistman SN, Martin GE (2009). BK Channels: mediators and models for alcohol tolerance. Trends Neurosci 32: 629-637.

Trougakos IP, Lourda M, Antonelou MH, Kletsas D, Gorgoulis VG, Papassideri IS et al. (2009). Intracellular clusterin inhibits mitochondrial apoptosis by suppressing p53-activating stress signals and stabilizing the cytosolic Ku70-Bax protein complex. Clin Cancer Res 15: 48-59.

Uhlen M, Ponten F (2005). Antibody-based proteomics for human tissue profiling. Mol Cell Proteomics 4: 384-393.

Vetulani J (2001). Drug addiction. Part II. Neurobiology of addiction. Pol J Pharmacol 53: 303-317.

Vogel C, Marcotte EM (2012). Insights into the regulation of protein abundance from proteomic and transcriptomic analyses. Nat Rev Genet 13: 227-232. Summarizes current understanding of the major factors regulating protein expression with emphasis on the role of post-transcriptional, translational, and degradation regulation of protein concentrations. 
Vogel N, Kluck CJ, Melzer N, Schwarzinger S, Breitinger U, Seeber S et al. (2009). Mapping of disulfide bonds within the amino-terminal extracellular domain of the inhibitory glycine receptor. J Biol Chem 284: 36128-36136.

Volkow N, Li TK (2005). The neuroscience of addiction. Nat Neurosci 8: 1429-1430.

Walter NAR, Bottomly D, Laderas T, Mooney MA, Darakjian P, Searles RP et al. (2009). High throughput sequencing in mice: a platform comparison identifies a preponderance of cryptic SNPs. BMC Genom 10: 379.

Wang J, Yuan W, Li MD (2011). Genes and pathways co-associated with the exposure to multiple drugs of abuse, including alcohol, amphetamine/methamphetamine, cocaine, marijuana, morphine, and/or nicotine: a review of proteomics analyses. Mol Neurobiol 44: 269-286. An overview of neuroproteomic studies related to drug addiction with insights into cellular activities and biological processes involved.

Wepf A, Glatter T, Schmidt A, Aebersold R, Gstaiger M (2009). Quantitative interaction proteomics using mass spectrometry. Nat Methods 6: 203-205.

Westerhoff HV, Palsson BO (2004). The evolution of molecular biology into systems biology. Nat Biotechnol 22: 1249-1252.

Weston AD, Hood L (2004). Systems biology, proteomics, and the future of health care: toward predictive, preventative, and personalized medicine. J Proteome Res 3: 179-196.

White AM, Ghia AJ, Levin ED, Swartzwelder HS (2000). Binge pattern ethanol exposure in adolescent and adult rats: differential impact on subsequent responsiveness to ethanol. Alcohol Clin Exp Res 24: 1251-1256.

Witzmann FA, Li J, Strother WN, McBride WJ, Hunter L, Crabb DW et al. (2003). Innate differences in protein expression in the nucleus accumbens and hippocampus of inbred alcohol-preferring and -nonpreferring rats. Proteomics 3: $1335-1344$

Witzmann FA, Strother WN (2004). Proteomics and alcoholism. Int Rev Neurobiol 61: 189-214.

Wong CCY, Mill J, Fernandes C (2011). Drugs and addiction: an introduction to epigenetics. Addiction 106: 480-489.

World Health Organization (2010): Global strategy to reduce the harmful use of alcohol. Available at: http://www.who.int/substance_abuse/publications/alcohol/ en/index.html.

Worst TJ, Tan JC, Robertson DJ, Freeman WM, Hyytia P, Kiianmaa K et al. (2005). Transcriptome analysis of frontal cortex in alcohol-preferring and nonpreferring rats. J Neurosci Res 80: 529-538.
Wu CC, MacCoss MJ, Howell KE, Matthews DE, Yates JR III (2004). Metabolic labeling of mammalian organisms with stable isotopes for quantitative proteomic analysis. Anal Chem 76: 4951-4959.

Wu CC, MacCoss MJ, Howell KE, Yates JR III (2003). A method for the comprehensive proteomic analysis of membrane proteins. Nat Biotechnol 21 : 532-538.

Wu S, Huang S, Ding J, Zhao Y, Liang L, Liu T et al. (2010). Multiple microRNAs modulate p21Cip1/Naf1 expression by directly targeting its $3^{\prime}$ untranslated region. Oncogene 29: 2302-2308.

Wurst FM, Kelso E, Weinmann W, Pragst F, Yegles M, Sundstrom Poromaa I (2008a). Measurement of direct ethanol metabolites suggests higher rate of alcohol use among pregnant women than found with the AUDIT—a pilot study in a populationbased sample of Swedish women. Am J Obstet Gynecol 198: e1-e5.

Wurst FM, Yegles M, Alling C, Aradottir S, Dierkes J, Wiesbeck GA et al. (2008b). Measurement of direct ethanol metabolites in a case of a former driving under the influence (DUI) of alcohol offender, now claiming abstinence. Int $J$ Legal Med 122: $235-239$.

Xuei X, Flury-Wetherill L, Dick D, Goate A, Tischfield J, Nurnberger J Jr et al. (2010). GABRR1 and GABRR2, encoding the GABA-A receptor subunits rho1 and rho2, are associated with alcohol dependence. Am J Med Genet B 153B: 418-427.

Young C, Klocke BJ, Tenkova T, Choi J, Labruyere J, Qin Y-Q et al. (2003). Ethanolinduced neuronal apoptosis in vivo requires BAX in the developing mouse brain. Cell Death Differ 10: 1148-1155.

Zembutsu H, Ohnishi Y, Tsunoda T, Furukawa Y, Katagiri T, Ueyama Y et al. (2002). Genome-wide cDNA microarray screening to correlate gene expression profiles with sensitivity of 85 human cancer xenografts to anticancer drugs. Cancer Res 62: $518-527$

Zhang B, Horvath S (2005). A general framework for weighted gene co-expression network analysis. Stat Appl Genet Mol Biol 4: Article17.

Zhang QC, Petrey D, Deng L, Qiang L, Shi Y, Thu CA et al. (2012). Structure-based prediction of protein-protein interactions on a genome-wide scale. Nature 490: 556-560

Zhao Y, Brasier AR (2013). Applications of selected reaction monitoring (SRM)-mass spectrometry (MS) for quantitative measurement of signaling pathways. Methods 61: 313-322.

Zhu W, Smith JW, Huang C-M (2010). Mass spectrometry-based label-free quantitative proteomics. J Biomed Biotechnol 2010: 840518. 